\title{
Các nhân tố ảnh hưởng đến thực thi logistics ngược: Nghiên cứu thực nghiệm cho ngành bán lẻ hàng điện tử tại Thành phố Đà Nẵng, Việt Nam
}

\section{Factors affecting reverse logistics implementation: Experimental research for electronic retail businesses in Da Nang City, Vietnam}

\author{
Nguyễn Huy Tuân ${ }^{1 *}$, Lê Tấn Bửu ${ }^{2}$ \\ ${ }^{1}$ Trường Đại học Duy Tân, Việt Nam \\ ${ }^{2}$ Trường Đại Kinh tế Thành phố Hồ Chí Minh, Việt Nam \\ "Tác giả liên hệ, Email: nhuytuandtu@ gmail.com
}

\section{THÔNG TIN}

DOI: $10.46223 /$ HCMCOUJS.

soci.vi.15.1.601.2020

Ngày nhận: 16/04/2020

Ngày nhận lại: 21/06/2020

Duyệt đăng: 07/07/2020

Tù khóa:

cam kết nguồn lực danh tiếng doanh nghiệp, khả năng công nghệ thông tin, thành phố môi trường, thực thi logistics ngược

\section{Keywords:}

resource commitment, corporate reputation, information technology capability, environmental city, reverse logistics implementation

\section{TÓM TÁT}

Nghiên cứu này tập trung xem xét các nhân tố ảnh hưởng đến Thực thi logistics ngược của doanh nghiệp kinh doanh bán lẻ hàng điện tử. Thông qua kết hợp phương pháp định tính và định lượng, mô hình lý thuyết được xác lập trong đó Danh tiếng doanh nghiệp được khám phá như là một nhân tố mới. Kết quả nghiên cứu thực nghiệm cho thấy Danh tiếng doanh nghiệp có tác động tích cực đến Thực thi logistics ngược và Cam kết nguồn lực. Trong khi đó, Cam kết nguồn lực có tác động gián tiếp đến Thực thi logistics ngược thông qua Khả năng công nghệ thông tin. Tuy nhiên, chưa có cơ sở để kết luận về sự ảnh hưởng trực tiếp của Cam kết nguồn lực đối với Thực thi logistics ngược. Nghiên cứu này cung cấp một số hàm ý hữu ích cho doanh nghiệp bán lẻ hàng điện tử trong việc nâng cao nhận thức cũng như phát triển tốt các kế hoạch cung ứng dịch vụ logistics ngược.

\section{ABSTRACT}

This study focuses on the antecedents of Reverse logistics implementation at electronic retailers. By adding Corporate reputation as a new factor, the new theoretical model is established through processing both qualitative and quantitative data. The results of experimental research state that Corporate reputation has a positive impact on Reverse logistics implementation and Resource commitment. Meanwhile, Resource commitment has an indirect impact on Reverse logistics implementation through Information technology capability. However, there is no evidence to show any direct influence of Resource commitment on Reverse logistics implementation. This study provides useful implications for electronic retailers to comprehend and develop plans for reverse logistics services. 


\section{Giới thiệu}

Từ năm 1970, thuật ngữ và các khái niệm liên quan đến logistics ngược (Reverse Logistics) đã xuất hiện không chỉ có vai trò quan trọng trong chuỗi cung ứng khép kín nói chung, mà còn rất được quan tâm trong chuỗi cung ứng xanh và bền vững (Govindan, Soleimani, \& Kannan, 2015), bên cạnh đó logistics ngược được hiểu là một quá trình con của quản lý thu hồi các sản phẩm hết thời gian sử dụng, bị hư hỏng, một quá trình thu gom, tái chế lại, sử dụng lại và xử lý các sản phẩm trả lại một cách phù hợp (Marchesini \& Alcântara, 2016). Bên cạnh chuỗi logistics xuôi xuất phát từ các nhà cung cấp ban đầu đến khách hàng tiêu dùng sau cùng vẫn thường được chú ý, thì ở dòng ngược lại của dòng vật chất bao gồm sản phẩm trả và bao bì đóng gói lại ngày càng xuất hiện nhiều hơn. Theo hướng dẫn về xử lý các chất thải trong lĩnh vực thiết bị điện và điện tử số 2002/96/EC tại châu Âu được ban hành vào năm 2003, các hoạt động thu gom, tái chế lại và tân trang, hồi phục các loại sản phẩm điện điện tử được yêu cầu mang tính bắt buộc là phải đạt tỷ lệ từ 4 kg/người/năm trở lên (Georgiadis \& Besiou, 2010).

Trong xu hướng hội nhập vào thị trường quốc tế, hoạt động logistics ngược ở quốc gia Việt Nam cũng nhận được nhiều sự quan tâm từ phía doanh nghiệp trong giai đoạn hiện nay. Kết quả ước tính cho thấy, chi phí đầu tư cho logistics ngược tại các doanh nghiệp chiếm từ $3 \%$ tới $15 \%$ tổng chi phí của các doanh nghiệp (Công ty $\mathrm{CP}$ Gemadept, 2018). Nhận thấy tầm quan trọng của logistics ngược, Thủ tướng Chính phủ quốc gia Việt Nam đã quy định các nội dung liên quan đến hoạt động thu hồi và xử lý các sản phẩm thải bỏ tại quyết định 16/2015/QĐ-TTg ngày 22/5/2015. Theo quyết định này, doanh nghiệp hoạt động trong lĩnh vực sản xuất, nhập khẩu cần thực hiện thiết lập các điểm thu gom, tiếp nhận các sản phẩm thải bỏ mà trước đó đã bán ra thị trường trong nước. Doanh nghiệp có trách nhiệm thông nhất cụ thể với khách hàng tiêu dùng về phương thức chuyển giao cũng như tiếp nhận đối với các sản phẩm thải bỏ, thực hiện vận chuyển sản phẩm thải bỏ đến điểm xử lý và có biện pháp xử lý các sản phẩm thải bỏ. Được xem như một trong những thành phố lớn trực thuộc Trung ương, Đà nẵng đã sớm đề ra mục tiêu phấn đấu trở thành thành phố môi trường, do đó chính quyền thành phố đã sớm ban hành Quyết định số 41/2008/QĐ-UBND về việc xây dựng Thành phố Đà Nẵng trở thành thành phố môi trường. Quyết định này yêu cầu toàn bộ người dân thành phố, các tổ chức cá nhân trong và ngoài nước đến làm việc và sinh sống tại Đà Nẵng cần tuân thủ ý thức bảo vệ môi trường. Các mục tiêu về việc thực hiện xã hội hóa công tác thu gom, vận chuyển và xử lý chất thải rắn và đặc biệt là tăng cường hoạt động tái chế chất thải rắn cũng được thành phố Đà Nẵng hết sức chú trọng, phấn đấu đạt $50 \%$ chất thải thu gom được tái chế. Điều này đã tác động đến hoạt động của các doanh nghiệp nói chung trên địa bàn thành phố Đà Nẵng trong đó có các doanh nghiệp kinh doanh bán lẻ hàng điện tử, một lĩnh vực được đánh giá là đang trong giai đoạn phát triển mạnh mẽ tại các thành phố lớn. Với dân số ước tính đến thời điểm hiện tại đạt khoảng 1,2 triệu người trong đó tỷ lệ dân cư sinh sống ở thành thị chiếm khoảng $87 \%$ đã mang lại một sức hút khá lớn đối với các doanh nghiệp bán lẻ hàng điện tử. Bên cạnh đó, để tăng cường trong việc thu hút khách hàng trong môi trường đầy cạnh tranh, các doanh nghiệp bán lẻ hàng điện tử tại thành phố Đà Nẵng ngày càng chú ý đến việc tuân thủ các chính sách bảo vệ người tiêu dùng, thực hiện công tác quản lý 
thu hồi, chính sách bảo hành, nhận trả hàng miễn phí, hỗ trợ sửa chữa, khắc phục các lỗi sản phẩm trả lại và thường xuyên nhận và giải đáp thông tin phản hồi từ phía khách hàng tiêu dùng.

Xem xét trong các lĩnh vực bán lẻ cho thấy hoạt động logistics ngược có vai trò hết sức quan trọng vì doanh nghiệp trong ngành bán lẻ có sự tiếp xúc trực tiếp với người tiêu dùng cuối cùng và do đó họ có thêm nhiều thông tin về nhu cầu và mong muốn của khách hàng (Parente \& Terepins, 2009). Bên cạnh đó các doanh nghiệp bán lẻ là chủ thể chính trong việc tuyên truyền các nguyên tắc, giá trị của xã hội (Parente \& Terepins, 2009) và trách nhiệm môi trường (Dias \& Braga, 2016). Bernon, Rossi, và Cullen (2011) chỉ ra rằng, mặc dù nhiều tác giả đã đóng góp vào sự phát triển lý thuyết về ứng dụng logistics ngược trong bán lẻ, nhưng vấn đề này có thể được coi là chưa thực sự lớn mạnh và đang phát triển, đặc biệt là trong lĩnh vực kinh doanh hàng điện tử. Các nghiên cứu về logistics ngược được tìm thấy nhiều ở các quốc gia nước ngoài nhưng ít được thực hiện tại thị trường Việt Nam. Trong xu thế hội nhập sâu rộng với thế giới, với thị trường có sức hút nhiều đối tác kinh doanh trong và ngoài nước, hoạt động kinh doanh ngày càng trở nên sôi động, đặc biệt là trong lĩnh vực bán lẻ hàng điện tử như điện thoại di động, máy ảnh, máy vi tính, ti vi, tủ lạnh, máy giặt, và nhiều các loại mặt hàng điện tử khác, do đó hoạt động logistics ngược tại Việt Nam cần được quan tâm hơn bao giờ hết để có thể đứng vững và phát triển hơn nữa trong môi trường cạnh tranh mang tính toàn cầu. Do đó bài báo này sẽ tập trung nghiên cứu các tác nhân của thực thi logistics ngược phù hợp với định hướng phát triển kinh tế gắn liền trách nhiệm bảo vệ môi trường của Thành phố Đà Nẵng.

\section{Cơ sở lý thuyết}

\section{Logistics ngugoc}

Từ những tài liệu nghiên cứu cho thấy các vấn đề liên quan đến logistics ngược đã xuất hiện cách đây nhiều thập kỷ, tuy nhiên logistics ngược được biểu hiện một cách khá rõ từ những năm 1970. Lúc này các thuật ngữ như kênh ngược, dòng ngược đã xuất hiện trong các tài liệu khoa học và phần lớn liên quan đến vấn đề tái chế (Guiltinan \& Nwokoye, 1975). Tiếp sau đó cũng có khá nhiều định nghĩa logistics ngược và theo thời gian ít nhiều có những sự thay đổi. Trong thập niên 80 , định nghĩa, khái niệm logistics ngược được đưa ra trong bối cảnh xuất hiện các luồng dịch chuyển sản phẩm đi theo hướng ngược so với các luồng truyền thống trong chuỗi cung ứng, lúc này logistics ngược được hiểu là đi theo đường sản phẩm hỏng (Lambert \& Stock, 1981). Stock (1992) cho rằng logistics ngược là một tập hợp các biện pháp nhằm thực hiện những hoạt động liên quan bao gồm tái chế, thay thế, tái sử dụng và xử lý phế thải. Pohlen và Theodore Farris (1992) đã khái niệm logistics ngược là sự chuyển động của hàng hóa từ người tiêu dùng hướng tới nhà sản xuất trong kênh phân phối. Vào cuối năm 1990, khái niệm về logistics ngược một lần nữa được đưa ra bởi RevLog (1998) và của Rogers và Tibben-Lembke (1999). Theo đó, logistics ngược được hiểu là quá trình lập kế hoạch, thực thi và kiểm soát các dòng ngược của nguyên liệu thô, sản phẩm dở dang, bao bì đóng gói và thành phẩm từ sản xuất, phân phối hoặc sử dụng đến điểm phục hồi hoặc điểm xử lý thích hợp.

Như vậy có khá nhiều khái niệm về logistics ngược trong các thập niên qua và điều này đã góp phần giúp các nhà nghiên cứu, các tổ chức, khách hàng có thể tiểp cận và thấu hiểu một cách khái quát nhất về logistics ngược. Nghiên cứu này cho rằng hai khái niệm logistics ngược được đưa ra bởi RevLog (1998) và Rogers và Tibben-Lembke (1999) có nhiều điểm tương đồng và đã thể hiện được tính bao quát của logistics ngược. Vì vậy bài báo tiếp cận logistics ngược như 
một quá trình phân phối ngược các nguyên vật liệu, bán thành phẩm, thành phẩm, bao bì đóng gói, và thông tin từ nơi sản xuất, phân phối hoặc tiêu thụ đến điểm xử lý thích hợp nhằm mang lại giá trị lợi ích kinh tế và/hoặc môi trường.

\section{Thỵc thi logistics ngực}

Như đã đề cập, logistics ngược là một quá trình tổng thể bao gồm việc lập kế hoạch, thực thi, kiểm soát các dòng ngược của vật chất nói chung như nguyên vật liệu, thành phẩm, sản phẩm dở dang, bao bì, và thông tin (Rogers \& Tibben-Lembke, 1999). Theo đó thực thi logistics ngược được hiểu là một quá trình con của logistics ngược. Trong nhiều tài liệu cho thấy thực thi logistics ngược được xem là một khái niệm nghiên cứu được đo lường thông qua các hoạt động cụ thể (Agle, Mitchell, \& Sonnenfeld, 1999; Blumberg, 1999; Ye, Zhao, Prahinski, \& Li, 2013). Vậy có thể đưa ra khái niệm rằng: Thực thi logistics ngược là việc thực hiện một hoặc một số các hoạt động thu gom, sửa chữa, tân trang, tái chế, và xử lý các nguyên vật liệu, bán thành phẩm, thành phẩm, bao bì đóng gói và thông tin trong một quá trình của logistics ngược.

Nhằm đảm bảo cơ sở vững chắc trong quá trình nghiên cứu thực hiện bài viết, các lý thuyết mang tính nền tảng được sử dụng bao gồm lý thuyết phát triển xã hội, danh tiếng doanh nghiệp, quan điểm dựa trên nguồn lực. Qua đó góp phần làm cơ sở cho việc biện luận hình thành các giả thuyết và mô hình nghiên cứu các nhân tố tác động đến Thực thi logistics ngược trong lĩnh vực kinh doanh bán lẻ các mặt hàng điện tử.

Lý thuyết về sụ phát triển xã hội được đề cập trong nghiên cứu của Cleveland và Jacobs (1999) về sự thay đổi tốt nhất mà xã hội mong muốn có được. Thuật ngữ phát triển được xem là việc dịch chuyển từ thấp đến cao về mức độ nhận thức, tính hiệu quả, chất lượng, hiệu suất và các thành quả. Lý thuyết về sự phát triển xã hội được sử dụng để lý giải cho quá trình phát triển, điều này sẽ giúp xác định được các tác nhân tác động đến sự phát triển và vai trò của những tác nhân này trong quá trình phát triển được xem xét đánh giá (Jacobs, Macfarlane, \& Asokan, 1997). Dựa vào bản chất cốt lõi của lý thuyết về sự phát triển, nghiên cứu này cho rằng sự phát triển của logistics ngược cũng bắt nguồn từ các tác nhân thuộc môi trường bên ngoài và bên trong của doanh nghiệp. Điều này sẽ ảnh hưởng đến công tác thực thi logistics ngược tại doanh nghiệp, nói cách khác là các tác nhân có thể làm tăng cường hoặc kìm hãm sự phát triển của hoạt động logistics ngược.

Lý thuyết quan điểm dỵa trên nguồn lục được đề cập trong nghiên cứu của Penrose (1959) về quan điểm dựa trên nguồn lực của hãng. Tác giả đã làm sáng tỏ mối quan hệ nhân quả giữa các nguồn lực, khả năng và lợi thế cạnh tranh, đóng góp cho sự hình thành lý thuyết về lợi thế cạnh tranh dựa trên nguồn lực. Theo lý thuyết này, doanh nghiệp được xem là một khối tập hợp các nguồn lực, do đó làm thế nào để doanh nghiệp hình thành được nguồn lực giá trị, khó bắt chước từ đối thủ cạnh tranh và không thể thay thế nhằm mang lại lợi thế cạnh tranh bền vững. Qua thời gian, lý thuyết quan điểm dựa trên nguồn lực tiếp tục được phát triển trong nghiên cứu của Barney (1991). Tác giả đã lập luận rằng lợi thế cạnh tranh bền vững xuất phát từ các nguồn lực và khả năng mà một hãng kiềm soát để đảm bảo nguồn lực và khả năng đó có giá trị, hiếm, không thể bắt chước và không thể thay thế. Nguồn lực của một doanh nghiệp có thể có hai loại đó là nguồn lực vô hình và nguồn lực hữu hình. Nguồn lực hữu hình là các tài sản vật chất như mặt bằng, nhà xưởng, máy móc thiết bị, nguồn lực vô hình chẳng hạn như kiến thức, trình độ của người lao động, kỹ năng quản lý, khả năng tổ chức các hoạt động trong doanh nghiệp (Barney, 1986; Wernerfelt, 1995). Lý thuyết quan điểm dựa trên nguồn lực xem xét vai trò quan trọng của nguồn lực bên trong doanh nghiệp nhằm tìm kiếm các giải pháp duy trì và nâng cao lợi thế cạnh 
tranh góp phần gia tăng kết quả hoạt động kinh doanh cho doanh nghiệp. Trên khía cạnh trách nhiệm môi trường đòi hỏi doanh nghiệp cân nhắc đến việc sử dụng nguồn lực vừa mang lợi ích cho doanh nghiệp nhưng không làm tổn hại đến môi trường (Zacharia, Sanders, \& Nix, 2011). Việc quản lý sử dụng nguồn lực gắn liền với hoạt động logistics xanh thực sự có ý nghĩa rất lớn đối với doanh nghiệp, do đó việc triển khai các hoạt động logistics ngược cũng cần phải đảm bảo giải quyết được các vấn đề môi trường. Bài viết này tiếp cận quan điểm dựa trên nguồn lực nhằm góp phần giải thích cách thức doanh nghiệp trong ngành bán lẻ hàng điện tử cam kết trong việc sử dụng nguồn lực trong thực thi logistics ngược nhằm mang lại giá trị lợi ích cho doanh nghiệp và các bên liên quan.

Lý thuyết danh tiếng doanh nghiệp: được sử dụng như là lý thuyết nền tảng của danh tiếng trong logistics ngược của doanh nghiệp bán lẻ. Danh tiếng doanh nghiệp được xem xét như là một tài sản vô hình có thể đóng góp vào lợi thế cạnh tranh trên thị trường hàng hóa và dịch vụ (Barney, 2014; Dowling, 1994). Dưới quan điểm dựa vào nguồn lực, danh tiếng có thể được xem là tài nguyên quý giá cần được doanh nghiệp quản lý (Dowling, 2000; Fombrun \& Shanley, 1990). Fombrun và Shanley (1990) cho rằng danh tiếng doanh nghiệp là kết quả của một quá trình cạnh tranh hướng tới việc tối đa hóa tình trạng kinh tế và phi kinh tế. Herbig và Milewicz (1993) đưa ra khái niệm danh tiếng như là sự tổng hợp của tất cả các giao dịch trước đó trong suốt vòng đời của thực thể và đòi hỏi sự nhất quán về hành động trong một thời gian dài. Doney và Cannon (1997) lập luận danh tiếng là mức độ mà các bên liên quan tin rằng doanh nghiệp đó trung thực và quan tâm đến khách hàng của mình. Do đó danh tiếng phản ánh mức độ mà doanh nghiệp đã làm tốt như thế nào trong sự xem xét của thị trường về khả năng của công ty để cung cấp kết quả có giá trị cho một nhóm các bên liên quan (Fombrun \& Rindova, 2000). Trong phạm vi liên quan đến lĩnh vực logistics ngược, nghiên cứu này xác định lựa chọn bối cảnh là danh tiếng trong logistics ngược của doanh nghiệp bán lẻ, biểu hiện sự nhận định đánh giá của các bên liên quan gồm chính phủ, nhà cung cấp, khách hàng, và đối thủ cạnh tranh đối với doanh nghiệp bán lẻ. Theo đó khái niệm danh tiếng trong logistics ngược của doanh nghiệp bán lẻ được đưa ra như sau: "Danh tiếng trong logistics ngược của doanh nghiệp bán lẻ (gọi tắt là danh tiếng doanh nghiệp) là đánh giá chung của các bên liên quan (gồm cơ quan chính phủ, khách hàng, nhà cung cấp và đối thủ cạnh tranh) dựa trên phản ứng của họ thông qua trải nghiệm trực tiếp hoặc gián tiếp đối với hoạt động logistis ngược mà doanh nghiệp bán lẻ thực hiện trong quá khứ."

\subsection{Khả năng công nghệ thông tin tác động đến thực thi logistics ngực}

Nhằm đáp ứng được sự thay đổi theo hướng ngày càng tốt hơn như đề cập trong lý thuyết về sự phát triển xã hội, một trong những yếu tố rất quan trọng đó là hệ thống công nghệ thông tin. Vận dụng vào lĩnh vực chuỗi cung ứng trong đó có logistics ngược cho thấy khả năng công nghệ thông tin là yếu tố then chốt tạo nên sự thành công của doanh nghiệp trong quá trình phát triển các hoạt động thuộc lĩnh vực này (Sundarraj \& Talluri, 2003). Thêm vào đó, sự lớn mạnh về nhu cầu thông tin tại các doanh nghiệp bán lẻ đã thúc đẩy nhu cầu công nghệ thông tin của các chủ thể thuộc chuỗi cung ứng (Ellram, La Londe, \& Weber, 1989). Khả năng công nghệ thông tin ngày càng được chú trọng tăng cường bởi vì điều này ảnh hưởng rất lớn đến hiệu quả quản lý và khả năng vận hành chuỗi cung ứng (Dawe, 1994). Bowersox và Daugherty (1995) cho rằng yếu tố quan trọng tạo nên sự khác biệt trong thực thi logistics ngược đó chính là hệ thống công nghệ thông tin hiện đại. Trong nghiên cứu của Daugherty, Myers, và Richey (2002) về vai trò của khả năng công nghệ thông tin đối với thực thi logistics ngược đã thể hiện rằng việc triển khai hiệu quả logistics ngược đòi hỏi phải chú ý tới việc ứng dụng hệ thống công nghệ thông tin. Closs, Goldsby, và Clinton (1997) cũng cho rằng thực thi logistics trong doanh nghiệp chịu sự ảnh hưởng 
khá lớn từ khả năng công nghệ thông tin. Nhiều tác giả khác cũng đã nhất trí cho rằng khả năng công nghệ thông tin sẽ góp phần thay đổi vị thế cạnh tranh trong lĩnh vực logistics ngược cũng như tạo nên sự khác biệt và ảnh hưởng trực tiếp đến kết quả kinh doanh của doanh nghiệp (Bowersox \& Daugherty, 1995; Closs \& Savitskie, 2003; Closs \& Xu, 2000; Corsi \& Boyson, 2003; Lewis \& Talalayevsky, 2000; Patterson, Grimm, \& Corsi, 2003). Vậy, giả thuyết được đặt ra như sau:

H1: Khả năng công nghệ thông tin có tác động cùng chiều đến thưc thi logistics ngược của doanh nghiệp bán lẻ

\subsection{Cam kết nguồn lục tác động đến thục thi logistics ngực}

Dựa trên cơ sở lý thuyết quan điểm dựa trên nguồn lực, phần này tập trung phân tích đến mối quan hệ giữa Cam kết nguồn lực và Thực thi logistics ngược. Nguồn lực có thể được phân loại thành nguồn lực tài chính, kỹ thuật và quản lý. Do đó Cam kết nguồn lực trong bối cảnh logistics ngược được hiểu là sự cam kết của doanh nghiệp về việc đầu tư các nguồn lực tài chính, kỹ thuật và quản lý nhằm đạt được mục tiêu trong quá trình thực thi logistics ngược (Day, 1994; Srinivasan, Lilien, \& Rangaswamy, 2002). Trong khi nguồn lực tài chính được sử dụng để tài trợ cho việc triển khai hoạt động logistics ngược, thì nguồn lực quản lý và nguồn lực kỹ thuật góp phần tạo nên năng lực thực thi logistics ngược. Cam kết của doanh nghiệp bán lẻ đối với nguồn lực kỹ thuật sẽ giúp nâng cao lợi thế cạnh tranh bền vững vì điều này vốn dĩ tạo ra khó sự khăn cho các đối thủ cạnh tranh trong việc bắt chước. Trong nghiên cứu của Zhou, Yim, và Tse (2005) đã thể hiện rằng doanh nghiệp bán lẻ thường có xu hướng cam kết đầu tư vào nguồn lực kỹ thuật nhằm mục tiêu không ngừng cải thiện khả năng thực thi logistics ngược mà họ mong muốn đạt được. Nhóm tác giả cho rằng việc đầu tư vào hệ thống công nghệ thông tin sẽ giúp phát triển khả năng thực thi logistics ngược, từ đó tăng hiệu quả hoạt động giữa doanh nghiệp bán lẻ và nhà cung cấp của họ. Tuy nhiên, để thực sự gia tăng được khả năng thực thi logistics ngược thì bên cạnh việc xem xét nguồn lực tài chính tài trợ đầu tư hệ thống công nghệ thông tin cần phải tính đến việc nâng cao công tác quản lý trong doanh nghiệp. Điều này có nghĩa là cần phải nâng cao kỹ năng quản lý, kiến thức quản lý cũng như sự am hiểu nắm bắt rõ toàn thể các thành viên, nhân viên dưới quyền trong nội bộ doanh nghiệp (Richey \& Wheeler, 2004). Từ những lập luận này, giả thuyết được đặt cho mối quan hệ giữa cam kết nguồn lực và thực thi logistics ngược là:

H2: Cam kết nguồn lục có tác động cùng chiều đến thực thi logistics ngược của doanh nghiệp bán lẻ

\subsection{Cam kết nguồn lục tác động đến khả năng công nghệ thông tin}

Mặc dù giữa cam kết nguồn lực và thực thi logistics ngược đã được dẫn chứng trong các lý thuyết liên quan, tuy nhiên chưa có nhiều hướng dẫn được cung cấp liên quan đến việc phân bổ nguồn lực trong bối cảnh logistics ngược. Vấn đề đặt ra là lĩnh vực hoặc hoạt động cụ thể nào mà người quản lý cần phải quan tâm đầu tư nguồn lực. Các nhà quản lý logistics ngược nhận thấy rằng yếu tố công nghệ thông tin là một trong những công cụ tốt nhất để nâng cao chất lượng dịch vụ của doanh nghiệp. Vì vậy ngày càng có nhiều doanh nghiệp đã tập trung sử dụng nguồn nhân lực, tài chính và vật chất để đầu tư vào hệ thống thông tin nhằm cải thiện sự đáp ứng và kiểm soát tốt logistics ngược. Lý thuyết quan điểm dựa vào nguồn lực là cơ sở cho thấy doanh nghiệp sẽ triển khai các nguồn lực nhằm đạt được khả năng công nghệ thông tin (Barney, 1986). Bằng cách cam kết đối với nguồn lực tài chính, quản lý và kỹ thuật đảm bảo cho hệ thống công nghệ thông tin được sử dụng trong quá trình logistics ngược, từ đó các nhà quản lý có thể cải thiện công tác truyền thông đến đối tác và tích hợp thông tin qua các hoạt động của doanh nghiệp. Khả năng 
công nghệ thông tin cao sẽ đóng vai trò đặc biệt quan trọng đối với thực thi logistics ngược của doanh nghiệp. Do đó giả thuyết được đặt ra là:

H3: Cam kết nguồn lực có tác động cùng chiều đến khả năng công nghệ thông tin của doanh nghiệp bán lẻ

\subsection{Danh tiếng doanh nghiệp tác động đến Thục thi logistics ngự̛̣ và Cam kết nguồn lục}

Thông qua thảo luận nhóm cùng các chuyên gia trong logistics ngược của doanh nghiệp bán lẻ trong bước nghiên cứu định tính đã phát hiện rằng Thực thi logistics ngược không chỉ chịu sự chi phối bởi cam kết nguồn lực, khả năng công nghệ thông tin, mà còn bị ảnh hưởng bởi danh tiếng của doanh nghiệp bán lẻ. Hơn nữa, trong bối cảnh logistics ngược, danh tiếng của doanh nghiệp bán lẻ ảnh hưởng đến cam kết nguồn lực. Theo quan điểm marketing, danh tiếng của doanh nghiệp được xem xét trong mối quan hệ giữa các bên hữu quan với doanh nghiệp. Danh tiếng doanh nghiệp được mô tả như là nhận thức và niềm tin mà các bên liên quan có đối với doanh nghiệp (Fombrun, 1996; Fombrun \& Shanley, 1990). Siltaoja (2006) định nghĩa danh tiếng như là những đánh giá lâu dài của các bên hữu quan, vì vậy doanh nghiệp bán lẻ cần xem xét làm thế nào để thực hiện cam kết của mình và đáp ứng mong đợi của các bên hữu quan đó. Nghiên cứu này cho rằng giữa danh tiếng và thực thi logistics ngược có sự ảnh hưởng qua lại lẫn nhau, việc các nhà bán lẻ thực thi logistics ngược tốt sẽ làm tăng danh tiếng. Ngược lại, với danh tiếng có được, bản thân doanh nghiệp sẽ có sự thôi thúc trong việc đáp ứng thực thi logistics ngược tốt hơn để có thể bảo vệ uy tín và tái khẳng định danh tiếng đã có. Tuy nhiên xuất phát từ mục tiêu và phạm vi nghiên cứu, nghiên cứu này quan tâm và tập trung làm rõ sự chi phối của danh tiếng đến thực thi logistics ngược của các nhà bản lẻ hàng điện tử. Hơn nữa, trong bối cảnh logistics ngược, doanh nghiệp bán lẻ càng có danh tiếng thì càng tăng cường trong công tác cam kết về các nguồn lực để nồ lực triển khai logistics ngược đáp ứng mong đợi từ phía khách hàng. Nhóm thực hiện bài viết này cho rằng vai trò của danh tiếng mà các chuyên gia nhận định là phù hợp với khía cạnh lý thuyết về danh tiếng của doanh nghiệp. Do đó sẽ rất có ý nghĩa khi xem xét các nhận định của các chuyên gia trong mô hình nghiên cứu. Vì vậy giả thuyết được đặt ra là:

H4: Danh tiếng doanh nghiệp có tác động cùng chiều đến thực thi logistics ngược của doanh nghiệp bán lẻ

H5: Danh tiếng doanh nghiệp có tác động cùng chiều đến cam kết nguồn lục của doanh nghiệp bán lẻ xuất.

Các giả thuyết nghiên cứu được tổng hợp trình bày tại Hình 1 - Mô hình nghiên cứu đề 


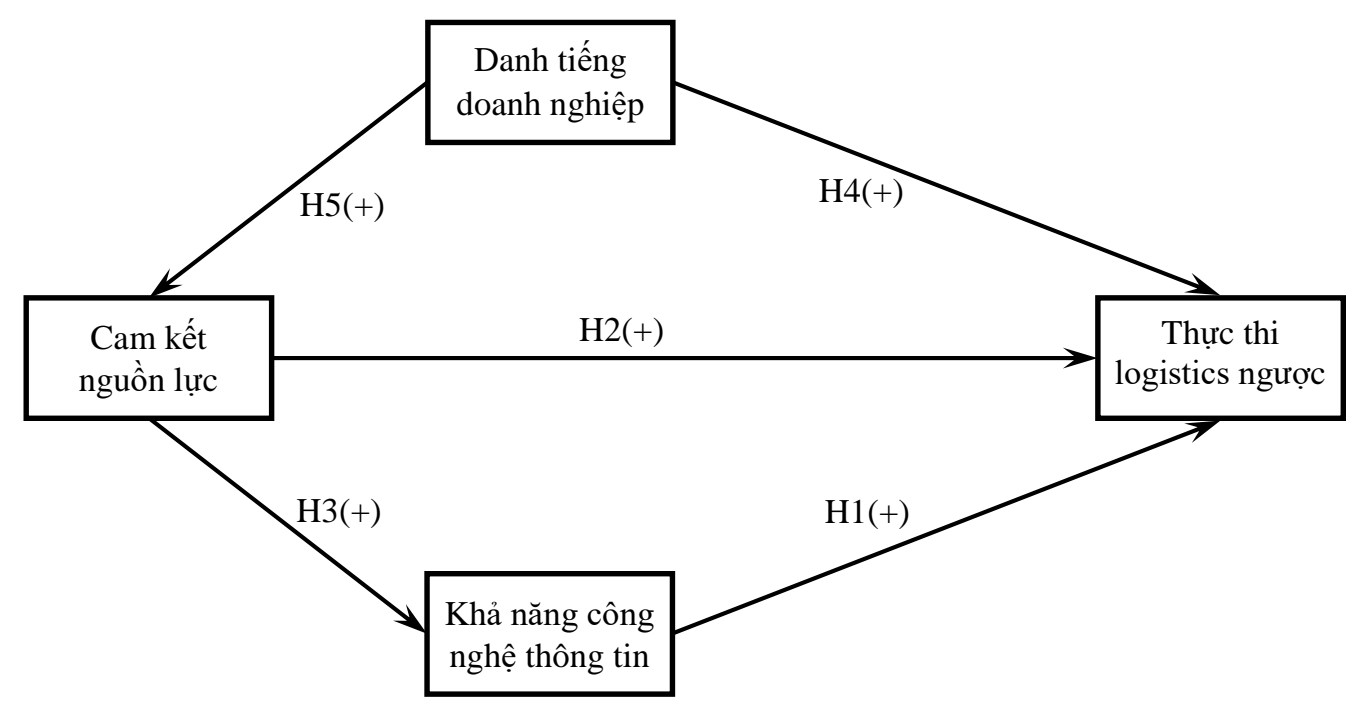

Hình 1. Mô hình nghiên cứu đề xuất

\section{Phương pháp nghiên cứu}

Nghiên cứu này được thực hiện thông qua hai giai đoạn đó là giai đoạn nghiên cứu sơ bộ và nghiên cứu chính thức.

Giai đoạn nghiên cứu sơ bộ sử dụng phương pháp nghiên cứu định tính dựa trên kỹ thuật thảo luận nhóm đối với các chuyên gia về logistics ngược (chuyên gia được xác định là người am hiểu về logistics ngược của doanh nghiệp bán lẻ hàng điện tử bao gồm: giám đốc, phó giám đốc, trưởng phòng kinh doanh, cán bộ chuyên trách phụ trách tiếp nhận, xử lý hàng trả lại và có ít nhất 5 năm kinh nghiệm). Thảo luận nhóm nhằm mục đích khám phá nhân tố mới ảnh hưởng đến logistics ngược, điều chỉnh và bổ sung các thang đo của các thành phần liên quan gồm các tác nhân trong logistics ngược và kết quả kinh tế. Số lượng trong thảo luận nhóm là 12 chuyên gia về logistics ngược trong các doanh nghiệp bán lẻ hàng điện tử.

Giai đoạn nghiên cứu chính thức sử dụng phương pháp nghiên cứu định lượng nhằm khẳng định lại các thành phần thang đo khái niệm nghiên cứu về logistics ngược cũng như tính toán độ tin cậy, thang đo giá trị các khái niệm nghiên cứu đó và kiểm định mô hình lý thuyết. Phần mềm AMOS (Analysis of Moment Structures) được ứng dụng trong bước nghiên cứu chính thức để thực hiện phân tích mô hình cấu trúc SEM (Structural Equation Modeling). Để có được số mẫu phù hợp cho việc khảo sát, các hướng dẫn xác định mẫu trước đây được xem xét, trong đó Hair, Black, Babin, và Anderson (1998) cho rằng nếu vận dụng phương pháp ML (Maximum Likelihood) thì số mẫu cần đạt từ 100 đến 150, Hoelter (1990) thì lại đưa ra quan điểm kích thước mẫu phải đạt tối thiểu là 200. Bollen (1989) cho rằng kích thước mẫu tối thiếu là 5 mẫu cho một biến quan sát. Hơn nữa để đảm bảo độ tin cậy trong quá trình nghiên cứu định lượng thì kích thước mẫu càng lớn được xem là càng tốt. Nghiễn cứu này tiến hành phát ra với số mẫu ban đầu là 420 mẫu, sau khi thu về có được 405 mẫu sử dụng được đảm bảo các yêu cầu tối thiểu về số mẫu của các tác giả tham chiếu ở trên. Việc chọn mẫu trong bước nghiên cứu chính thức này cũng được thực hiện bằng cách lấy mẫu thuận tiện phi xác suất từ các doanh nghiệp bán lẻ hàng điện tử có địa điểm làm việc trên địa bàn Thành phố Đà Nẵng. Từ mỗi doanh nghiệp được chọn đó sẽ mời 01 người đại diện am hiểu về logistics ngược (người đại diện có thể là giám đốc, hoặc phó giám đốc, hoặc trưởng phòng 
kinh doanh, hoặc cán bộ chuyên trách hoạt động tiếp nhận và xử lý hàng trả lại và có ít nhất từ 2 năm kinh nghiệm trở lên). Việc thu thập thông tin được thực hiện bằng cách tiến hành phỏng vấn trực tiếp thông qua bảng khảo sát được thiết lập sẵn. Trong đó tập trung vào việc thu thập thông tin trả lời các câu hỏi nhận định tương ứng với thang đo lường của các nhân tố Thực thi logistics ngược, Cam kết nguồn lực, Khả năng công nghệ thông tin và Danh tiếng doanh nghiệp. Người được tham gia khảo sát sẽ trả lời trên thang điểm Likert từ 1 đến 5 điểm (tương ứng với các mức độ từ hoàn toàn đồng ý đến hoàn toàn không đồng ý). Ngoài ra, một số thông tin liên quan đến người tham gia khảo sát chẳng hạn như chức vụ, giới tính và thâm niên công tác cũng được thu thập trong quá trình thực hiện khảo sát.

\section{Quy trình nghiên cứu:}

Quy trình nghiên cứu được thực hiện thông qua hai giai đoạn: Giai đoạn 1-giai đoạn nghiên cứu sơ bộ bằng phương pháp định tính, giai đoạn 2-giai đoạn nghiên cứu chính thức bằng phương pháp định lượng. Để thực hiện giai đoạn 1 - Nghiên cứu định tính: tác giả tiến hành tổng hợp các tài liệu, thực hiện nghiên cứu lý thuyết logistics ngược và tiếp cận thang đo đo lường Thực thi logistics ngược, Cam kết nguồn lực, Khả năng công nghệ thông tin, và hình thành bảng tổng hợp về thang đo lường các khái niệm nghiên cứu. Tiến hành phác thảo bản dàn ý thảo luận nhóm, lên kế hoạch thời gian và địa điểm cho buổi thảo luận nhóm và tiếp theo là thực hiện thảo luận nhóm. Theo đó 12 chuyên gia được mời một cách thuận tiện am hiểu trong lĩnh vực logistics ngược tham dự thảo luận nhóm trong khoảng thời gian từ 8h30 - 11h00 ngày 09/4/2019 tại phòng họp của Công ty Karuto tại Thành phố Đà Nẵng, trong đó có: 01 chuyên gia là giám đốc, với 8 năm kinh nghiệm, có trình độ thạc sỹ Quản trị kinh doanh, và hoạt động trong lĩnh vực kinh doanh bán lẻ hàng điện máy điện tử; 02 chuyên gia là phó giám đốc, trong đó 01 phó giám đốc có trình độ thạc sỹ kinh tế có thâm niên công tác 9 năm, hoạt động trong lĩnh vực kinh doanh bán lẻ hàng điện tử gia dụng, và 01 phó giám đốc có trình độ cử nhân quản trị kinh doanh với 8 năm kinh nghiệm trong lĩnh vực kinh doanh bán lẻ hàng điện tử; 04 chuyên gia là trưởng phòng kinh doanh với trình độ cử nhân kinh tế, quản trị kinh doanh, có tối thiểu 5 năm kinh nghiệm hoạt động trong lĩnh vực kinh doanh bán lẻ hàng điện tử (ti vi, máy vi tính, máy giặt, điện thoại di động, máy điều hòa nhiệt độ, tủ lạnh, và một số mặt hàng điện tử khác); và 05 chuyên gia là cán bộ chuyên trách phụ trách hoạt động tiếp nhận và xử lý hàng trả lại, các chuyên gia cán bộ chuyên trách này có kinh nghiệm công tác từ 5 đến 7 năm trong lĩnh vực kinh doanh bán lẻ mặt hàng điện tử, trong đó có 02 cán bộ có trình độ kỹ sư trong lĩnh vực công nghệ thông tin và điện máy, 03 cán bộ có trình độ cử nhân quản trị kinh doanh. Như vậy, phần lớn các chuyên gia đều có trình độ từ cử nhân, kỹ sư đại học trở lên, có ít nhất là 5 năm kinh nghiệm và tất cả các chuyên gia đều làm việc trong lĩnh vực bán lẻ hàng điện tử. Trong giai đoạn 2 - Nghiên cứu định lượng được thực hiện bằng cách tiến hành khảo sát, nhập liệu, đánh giá độ tin cậy của thang đo bằng kỹ thuật phân tích độ tin cậy Cronbach's Apha và nhân tố khám phá EFA, tiếp đến là tiến hành phân tích nhân tố khẳng định CFA và phân tích SEM. Ngoài ra nghiên cứu cũng thực hiện kiểm định mô hình lý thuyết và kiểm định các giả thuyết nghiên cứu.

\section{Kết quả nghiên cứu định tính:}

Một trong những phát hiện trong quá trình thảo luận nhóm là phần lớn các chuyên gia nhận định rằng Thực thi logistics ngược không chỉ bị ảnh hưởng bởi Cam kết nguồn lực, Khả năng công nghệ thông tin, mà còn bị ảnh hưởng bởi Danh tiếng trong logistics ngược của doanh nghiệp bán lẻ. Bên cạnh đó, các chuyên gia có những gợi ý rằng những ấn tượng của các bên hữu quan về hoạt động logistics ngược, sự uy tín trong việc đáp ứng khách hàng thông 
qua hoạt động logistics ngược sẽ góp phần thôi thúc doanh nghiệp bán lẻ tăng cường bảo vệ danh tiếng vốn có của mình. Từ những gợi ý này và kết hợp lý thuyết danh tiếng doanh nghiệp, nghiên cứu này đưa ra khái niệm danh tiếng doanh nghiệp trong logistics ngược như sau:

Danh tiếng trong logistics ngược của doanh nghiệp bán lẻ (gọi tắt là danh tiếng doanh nghiệp) là đánh giá chung của các bên liên quan (gồm cơ quan chính phủ, khách hàng, nhà cung cấp và đối thủ cạnh tranh) dựa trên phản ứng của họ thông qua trải nghiệm trực tiếp hoặc gián tiếp đối với hoạt động logistis ngược mà doanh nghiệp bán lẻ thực hiện trong quá khứ.

Bước nghiên cứu định tính cũng cho kết quả về mối quan hệ giữa Danh tiếng doanh nghiệp và Cam kết nguồn lực. Điều này có nghĩa là khi một doanh nghiệp bán lẻ hàng điện tử càng có danh tiếng thì càng tăng cường trong công tác cam kết nguồn lực để nỗ lực thực thi logistics ngược đáp ứng nhu cầu của thị trường. Tác giả cho rằng vai trò của danh tiếng mà các chuyên gia nhận định là phù hợp với khía cạnh lý thuyết về danh tiếng của doanh nghiệp. Một kết quả nữa trong nghiên cứu định tính được thể hiện đó là các chuyên gia cho rằng thang đo lường của Thực thi logistics ngược, $\mathrm{Cam}$ kết nguồn lực, Khả năng công nghệ thông tin, và Kết quả kinh tế là dễ hiểu và hợp lý. Từ những gợi ý này và kết hợp lý thuyết danh tiếng doanh nghiệp, thang đo Danh tiếng doanh nghiệp trong logistics ngược của doanh nghiệp bán lẻ được phát triển và nhận được sự nhất trí từ các chuyên gia trong quá trình thảo luận nhóm.

\section{Đo lường:}

Với các nhân tố đã xác định bao gồm Thực thi logistics ngược, Cam kết nguồn lực, Khả năng công nghệ thông tin và Danh tiểng doanh nghiệp, tiến hành xem xét các tài liệu thu thập cũng như tiểp thu các ý kiến đóng góp của các chuyên gia, thang đo lường các nhân tố này được phát triển với thang điểm Likert từ 1 đến 5 điểm tương ứng với các mức độ hoàn toàn đồng ý đến hoàn toàn không đồng ý. Một vài điều chỉnh nhỏ từ các thang đo trước đây để đảm bảo sự phù hợp với điều thực tiễn của doanh nghiệp trong ngành bán lẻ hàng điện tử tại Thành phố Đà Nẵng, Việt Nam.

Thưc thi logistics ngượ: dựa trên các quan điểm đa dạng của các tác giả như Agle và cộng sự (1999), và Ye và cộng sự (2013) dưới nền tảng của khái niệm logistics ngược. Theo đó logistics ngược được hiểu là sự chuyển dịch của sản phẩm hoặc vật liệu từ khách hàng cuối sang nhà cung cấp cho mục đích kinh tế, môi trường và hoạt động sửa chữa được thực hiện nhằm tạo ra hoặc lấy lại giá trị hoặc xử lý thích hợp (Blumberg, 1999; Carter \& Ellram, 1998; Rogers \& Tibben-Lembke, 1999).

Cam kết nguồn lự: Cam kết nguồn lực được đo bằng ba biến quan sát dựa trên các nguồn tài chính, kỹ thuật và quản lý được cam kết trong logistics ngược. Các nhà quản lý của doanh nghiệp bán lẻ kinh doanh sản phẩm điện tử sẽ được hỏi để chỉ ra mức độ đầu tư vào các nguồn lực tài chính, kỹ thuật, nguồn lực quản lý hướng tới phát triển thực thi logistics ngược (Jack, Powers, \& Skinner, 2010).

Khả năng công nghệ thông tin: Khả năng công nghệ thông tin được sử dụng để đánh giá hiệu quả của doanh nghiệp sử dụng công nghệ trong quản lý quá trình logistics ngược. Khả năng công nghệ thông tin giúp giải quyết các năng lực trong truyền thông, định tuyển, lưu trữ và thông tin. Do đó các thành phần của quản lý thông tin được xem như là yếu tố cốt lõi của khả năng công nghệ thông tin của một doanh nghiệp (Autry, Daugherty, \& Richey, 
2001). Thang đo lường khả năng của công nghệ thông tin được xem xét gồm 5 biến quan sát và đảm bảo được các yêu cầu về độ tin cậy.

Danh tiếng doanh nghiệp: dựa vào lý thuyết nền tảng về danh tiếng doanh nghiệp và cũng như thu nhận ý kiến của các chuyên gia trong quá trình thảo luận nhóm, đồng thời tiếp cận thang đo lường mà Walsh và Beatty (2007) đã sử dụng nhằm đánh giá các công ty dịch vụ với 5 khía cạnh bao gồm: khách hàng, người sử dụng lao động, sự tin cậy về tài chính, chất lượng sản phẩm và dịch vụ, và trách nhiệm xã hội và môi trường. Tuy nhiên nghiên cứu này xem xét thang đo danh tiếng doanh nghiệp đối với khía cạnh khách hàng, chất lượng dịch vụ, và trách nhiệm xã hội và môi trường và có được thang đo gồm 10 biến quan sát để đưa vào sử dụng.

\section{Kết quả nghiên cứu và thảo luận}

\subsection{Thông tin mẫu nghiên cứu}

Mẫu nghiên cứu được sử dụng có tỷ lệ nam chiếm $61.5 \%$ và tỷ lệ nữ chiếm $38.5 \%$. Trong 405 đối tượng tham gia khảo sát có 31 người là giám đốc chiếm $7.7 \%, 81$ người là phó giám đốc doanh nghiệp chiếm 20.0\%, 143 người là trưởng phòng kinh doanh chiếm $35.3 \%$, và còn lại là 150 cán bộ chuyên trách về tiếp nhận và xử lý sản phẩm trả lại chiếm $37.0 \%$. Có $89.1 \%$ đối tượng được khảo sát có thâm niên công tác từ 3 năm trở lên, chỉ có $10.9 \%$ đối tượng khảo sát có thâm niên công tác là 2 năm. Cụ thể trong 405 người được khảo sát có 78 người có thâm niên công tác trên 5 năm chiếm tỷ lệ $19.3 \%, 124$ người có thâm niên công tác 5 năm chiếm tỷ lệ $30.6 \%, 73$ người có thâm niên công tác 4 năm chiếm tỷ lệ $18.0 \%, 86$ người có thâm niên công tác 3 năm chiếm tỷ lệ $21.2 \%$, và có 44 người có thâm niên công tác 2 năm chiếm tỷ lệ $10.9 \%$.

\subsection{Kết quả phân tích Cronbach's Alpha và EFA}

Cộng cụ sử dụng phân tích độ tin cậy Cronbach's Alpha được sử dụng trước để loại những biển không phù hợp (Hair, Black, Babin, \& Anderson, 2010). Các biến có hệ số tương quan biến tổng (item-total correlation) nhỏ hơn 0.3 sẽ bị loại, hoặc biến quan sát cũng sẽ bị loại nếu điều này làm tăng hệ số tin cậy Cronbach'sAlpha. Việc chọn thang đo khi thỏa mãn tiêu chuẩn hệ số tin cậy Cronbach's Alpha từ 0.6 trở lên. Tiếp theo là tiến hành phân tích nhân tố khám phá EFA trong đó sử dụng phương pháp Principal Components với phép trích theo số nhân tố cố định và phép quay Promax. Điều kiện để chấp nhận thang đo trong phân tích EFA bao gồm: (i) hệ số KMO (Kaiser Meyer Olkin) lớn hơn 0.6 với kết quả kiểm định Bartlett có ý nghĩa thống kê $(\mathrm{Sig}$. $<0.05)$; (ii) các biến quan sát có hệ số tải nhân tố (factor loading) lớn hơn 0.5 ; và (iii) tổng phần trăm phương sai trích (Cumulative \%) đạt từ $50 \%$ trở lên.

\section{Bảng 1}

Thang đo cuối trong phân tích Cronbach's Alpha và EFA

\begin{tabular}{|l|l|c|c|c|}
\hline \multicolumn{1}{|c|}{ Biến quan sát } & Mã hóa & $\begin{array}{c}\text { Tương } \\
\text { quan } \\
\text { biến-tổng }\end{array}$ & $\begin{array}{c}\text { Cronbach's } \\
\text { Alpha nếu } \\
\text { loại biến }\end{array}$ & $\begin{array}{c}\text { Hệ số tải } \\
\text { nhân tố }\end{array}$ \\
\hline $\begin{array}{c}\text { + Danh tiếng doanh nghiệp } \\
\text { «Cronbach's Alpha }=\mathbf{0 . 9 3 5 ~ » ~}\end{array}$ & DTN & & & \\
\hline $\begin{array}{l}\text { Hoạt động thực thi logistics ngược của chúng } \\
\text { tôi được đánh giá là đáng tin cậy }\end{array}$ & DTN7 & 0.807 & 0.923 & 0.829 \\
\hline
\end{tabular}




\begin{tabular}{|c|c|c|c|c|}
\hline Biến quan sát & Mã hóa & $\begin{array}{c}\text { Tương } \\
\text { quan } \\
\text { biến-tổng }\end{array}$ & $\begin{array}{l}\text { Cronbach's } \\
\text { Alpha nếu } \\
\text { loại biến } \\
\end{array}$ & $\begin{array}{l}\text { Hệ số tải } \\
\text { nhân tố }\end{array}$ \\
\hline $\begin{array}{l}\text { Công ty chúng tôi được đánh giá là: khách } \\
\text { hàng luôn nhận được sự quan tâm từ công ty } \\
\text { chúng tôi đối với nhu cầu trả lại sản phẩm của } \\
\text { khách hàng }\end{array}$ & DTN1 & 0.799 & 0.924 & 0.809 \\
\hline $\begin{array}{l}\text { Công ty chúng tôi được đánh giá là luôn đảm } \\
\text { bảo quyền lợi của khách hàng trả lại hàng một } \\
\text { cách nghiêm túc }\end{array}$ & DTN4 & 0.791 & 0.925 & 0.748 \\
\hline $\begin{array}{l}\text { Công ty chúng tôi được đánh giá là thực thi } \\
\text { logistics ngược mang lại giá trị thỏa đáng cho } \\
\text { khách hàng trả lại sản phẩm }\end{array}$ & DTN9 & 0.784 & 0.925 & 0.707 \\
\hline $\begin{array}{l}\text { Công ty chúng tôi được đánh giá là luôn nỗ lực } \\
\text { trong thực thi logistics ngược gắn liền với trách } \\
\text { nhiệm xã hội và môi trường }\end{array}$ & DTN10 & 0.784 & 0.925 & 0.695 \\
\hline $\begin{array}{l}\text { Công ty chúng tôi được đánh giá là luôn có thái } \\
\text { độ một cách nhã nhặn, lịch sự đối với khách } \\
\text { hàng trả lại sản phẩm }\end{array}$ & DTN2 & 0.785 & 0.925 & 0.678 \\
\hline $\begin{array}{l}\text { Công ty chúng tôi được đánh giá là luôn quan } \\
\text { tâm đến tất cả các khách hàng với bất kể giá trị } \\
\text { nào của sản phẩm trả lại }\end{array}$ & DTN5 & 0.770 & 0.926 & 0.622 \\
\hline $\begin{array}{l}\text { + Khả năng công nghệ thông tin } \\
\text { «Cronbach's Alpha }=0.896 \text { » }\end{array}$ & $\mathrm{KCN}$ & & & \\
\hline $\begin{array}{l}\text { Hệ thống công nghệ thông tin của công ty } \\
\text { chúng tôi có khả năng truyền thông bên ngoài } \\
\text { với các nhà cung cấp }\end{array}$ & KCN2 & 0.761 & 0.870 & 0.839 \\
\hline $\begin{array}{l}\text { Hệ thống công nghệ thông tin của công ty } \\
\text { chúng tôi có khả năng giải quyết lộ trình thực } \\
\text { thi logistics ngược }\end{array}$ & KCN1 & 0.732 & 0.876 & 0.769 \\
\hline $\begin{array}{l}\text { Hệ thống công nghệ thông tin của công ty } \\
\text { chúng tôi có khả năng tích hợp các thông tin trả } \\
\text { lại hàng vào cơ sở dữ liệu }\end{array}$ & KCN4 & 0.744 & 0.873 & 0.655 \\
\hline $\begin{array}{l}\text { Hệ thống công nghệ thông tin của công ty } \\
\text { chúng tôi có khả năng truyền thông bên ngoài } \\
\text { với khách hàng tiêu dùng }\end{array}$ & KCN3 & 0.735 & 0.875 & 0.655 \\
\hline $\begin{array}{l}\text { Hệ thống công nghệ thông tin của công ty } \\
\text { chúng tôi có khả năng cung cấp thông báo tiến } \\
\text { độ về hàng trả lại sẽ được nhận }\end{array}$ & KCN5 & 0.747 & 0.873 & 0.568 \\
\hline $\begin{array}{l}\text { + Thục thi logistics ngược } \\
\text { «Cronbach's Alpha }=0.927 »\end{array}$ & TTL & & & \\
\hline $\begin{array}{l}\text { Chúng tôi thu gom và vận chuyển sản phẩm và } \\
\text { bao bì trả lại. }\end{array}$ & TTL1 & 0.810 & 0.910 & 0.757 \\
\hline $\begin{array}{l}\text { Chúng tôi trả lại các sản phẩm cho nhà cung } \\
\text { cấp }\end{array}$ & TTL6 & 0.818 & 0.908 & 0.711 \\
\hline $\begin{array}{l}\text { Trong phạm vi và khả năng của mình, chúng } \\
\text { tôi sửa chữa, tân trang các sản phẩm và bao bì } \\
\text { đóng gói trả lại. }\end{array}$ & TTL4 & 0.820 & 0.908 & 0.702 \\
\hline $\begin{array}{l}\text { Chúng tôi thu hồi các sản phẩm có vấn đề về } \\
\text { chất lượng. }\end{array}$ & TTL2 & 0.798 & 0.912 & 0.683 \\
\hline
\end{tabular}




\begin{tabular}{|c|c|c|c|c|}
\hline Biến quan sát & Mã hóa & $\begin{array}{c}\text { Tương } \\
\text { quan } \\
\text { biến-tổng }\end{array}$ & $\begin{array}{c}\text { Cronbach's } \\
\text { Alpha nếu } \\
\text { loại biến }\end{array}$ & $\begin{array}{l}\text { Hệ số tải } \\
\text { nhân tố }\end{array}$ \\
\hline $\begin{array}{l}\text { Chúng tôi sửa chữa và cung cấp dịch vụ bảo trì } \\
\text { sau bán. }\end{array}$ & TTL3 & 0.792 & 0.913 & 0.652 \\
\hline $\begin{array}{l}\text { + Cam kết nguồn lực } \\
\text { «Cronbach's Alpha }=0.885 \text { » }\end{array}$ & CNL & & & \\
\hline $\begin{array}{l}\text { Chúng tôi cam kết đảm bảo về nguồn lực quản } \\
\text { lý cho việc thực thi logistics ngược }\end{array}$ & CNL3 & 0.766 & 0.847 & 0.879 \\
\hline $\begin{array}{l}\text { Chúng tôi cam kết đảm bảo về nguồn lực kỹ } \\
\text { thuật cho việc thực thi logistics ngược }\end{array}$ & CNL1 & 0.781 & 0.834 & 0.811 \\
\hline $\begin{array}{l}\text { Chúng tôi cam kết đảm bảo về nguồn lực tài } \\
\text { chính cho việc thực thi logistics ngược }\end{array}$ & CNL2 & 0.784 & 0.831 & 0.716 \\
\hline
\end{tabular}

Nguồn: Trích xuất từ phân tích dữ liệu thu thập

Bảng 1 trình bày thang đo cuối trong phân tích Cronbach's Alpha và nhân tố khám phá EFA. Hệ số Cronbach's Alpha đạt từ 0.6 trở lên cho mỗi nhân tố, hệ số tương quan biến tổng của các biến quan sát đạt yêu cầu $(>0.3)$. Hệ số KMO đạt mức cao 0.980 , và hệ số tải nhân tố tương ứng với các biến quan sát đảm bảo lớn hơn 0.5 trong đó đạt lớn nhất là 0.879 đối với biến quan sát CNL3 và nhỏ nhất là 0.568 tại biến quan sát KCN5. Do đó thang đo đo lường các nhân tố Danh tiếng doanh nghiệp, Khả năng công nghệ thông tin, Thực thi logistics ngược và Cam kết nguồn lực được chấp nhận và đảm bảo yêu cầu về độ tin cậy.

So với thang đo gốc ban đầu, một số biến quan sát bị loại do không đảm bảo được yêu cầu về độ tin cậy bao gồm: TTL5 (Trong phạm vi và khả năng của mình, chúng tôi tháo gỡ các sản phẩm trả lại không sử dụng được để thu hồi các nguyên vật liệu cho việc tái sử dụng). Tác giả nhận thấy việc tháo gỡ các sản phẩm điện tử trả lại để thu hồi các nguyên vật liệu có thể nằm ngoài phạm vi khả năng của doanh nghiệp bán lẻ, điều này cho thấy việc loại bỏ TTL5 là phù hợp trong thực tế; DTN3 (Công ty chúng tôi được đánh giá là luôn đối xử một cách công bằng với các khách hàng trả lại sản phẩm), DTN8 (Công ty chúng tôi được đánh giá là luôn có sự đổi mới tích cực trong quá trình thực thi logistics ngược), DTN6 (Công ty chúng tôi được đánh giá là cung cấp dịch vụ trong quá trình thực thi logistics ngược đảm bảo có chất lượng cao). Kết quả cho thấy thang đo lường của Danh tiếng doanh nghiệp bán lẻ trong logistics ngược dựa trên cảm nhận của họ về đánh giá chung của khách hàng, cơ quan chính phủ, nhà cung cấp, và đối thủ cạnh tranh đối với hoạt động thực thi logistics ngược.

\subsection{Kết quả phân tích nhân tố khẳng định CFA và phân tích SEM}

Phân tích CFA giúp kiểm định cấu trúc lý thuyết của thang đo lường, xem xét mối quan hệ giữa một khái niệm nghiên cứu với các khái niệm khác (Steenkamp \& van Trijp, 1991). Mô hình được xem là tương thích và phù hợp với dữ liệu nghiên cứu khi các giá trị TLI (Tucker \& Lewis index) và CFI (Coparative Fit Index) từ 0.90 đến 1.00 , Chi-bình phương điều chỉnh theo bậc tự do CMIN/df đạt giá trị nhỏ hơn 3.00, RMSEA (Root Mean Square Error Approximation) đạt giá trị nhỏ hơn 0.08 . Ngoài ra, Hair và cộng sự (2010) cho rằng một thang đo đảm bảo độ tin cậy khi trọng số chuẩn hóa $\lambda i$ lớn hơn bằng 0.50 (lý tưởng nhất là từ 0.70 trở lên) và hệ số CR lớn hơn 0.70, đạt hội tụ khi phương sai trích AVE (Average Variance Extracted) lớn hơn 0.50. Hai khái niệm đạt giá trị phân biệt khi có hệ số tương quan giữa chúng nhỏ hơn 1.00. Các chỉ tiêu này được sử dụng trong việc đánh giá thang đo của các khái niệm nghiên cứu. 


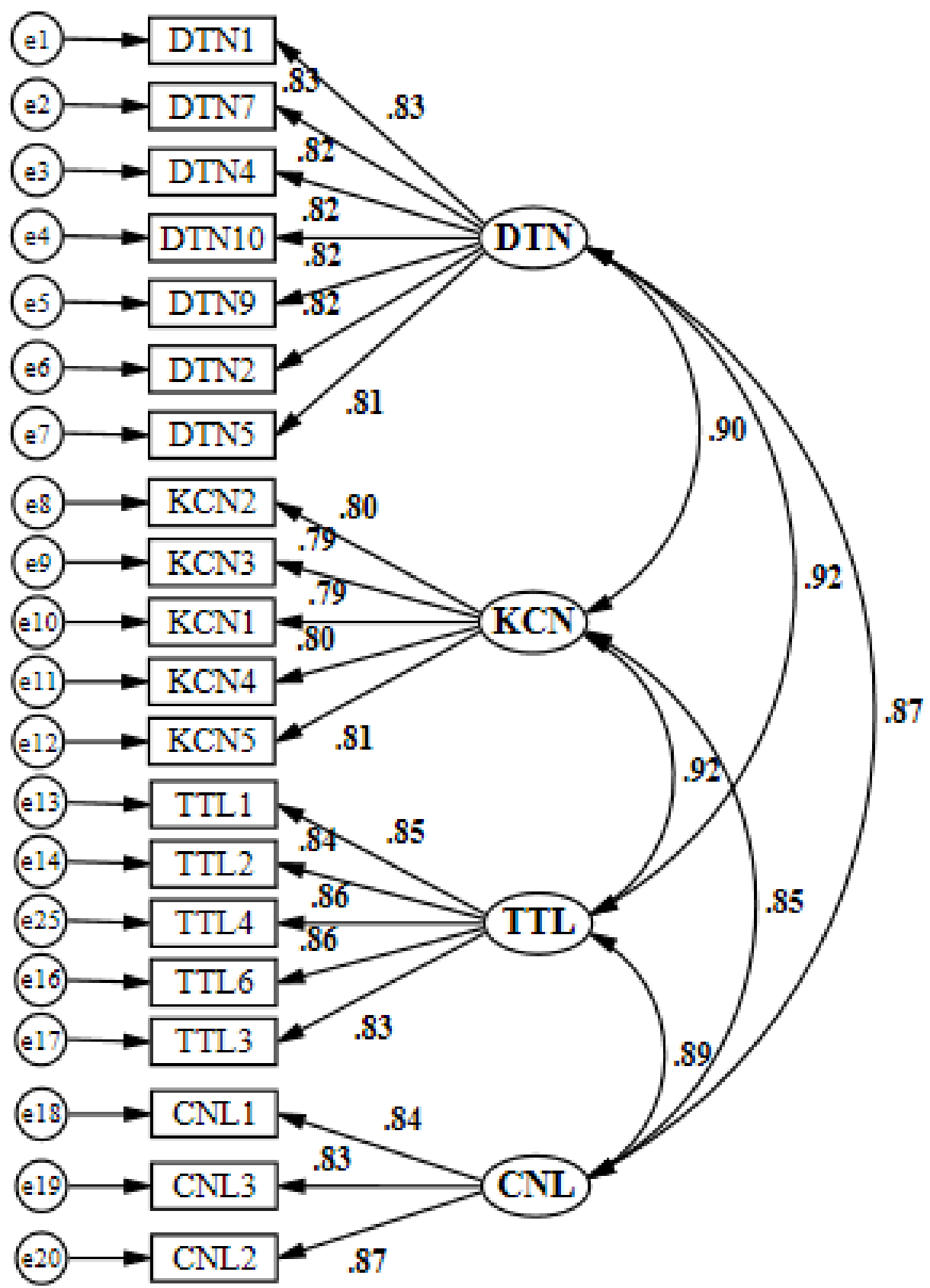

Hình 2. Kết quả CFA (chuẩn hóa) mô hình tới hạn

Mô hình đo lường tới hạn thể hiện các mối quan hệ lẫn nhau của 04 khái niệm nghiên cứu với kết quả thể hiện tại Hình 2 . Kết quả phân tích cho thấy các chỉ tiêu đo lường phù hợp $(\mathrm{CMIN} / \mathrm{df}=1.226<3.00, \mathrm{CFI}=0.995>0.90, \mathrm{TLI}=0.994>0.90, \mathrm{RMSEA}=0.024<0.08)$. Vậy mô hình đo lường tới hạn đảm bảo tính tương thích và phù hợp với dữ liệu nghiên cứu. Kết quả cũng cho thấy tất cả các thang đo bao gồm TTL, DTN, KCN và CNL đều đạt tính đơn hướng. 


\section{Bảng 2}

Độ tin cậy tổng hợp, phương sai trích trung bình và hệ số tương quan

\begin{tabular}{|l|c|c|c|c|c|c|}
\hline \multirow{2}{*}{ Nhân tố } & \multirow{2}{*}{ CR } & \multirow{2}{*}{ AVE } & \multicolumn{4}{|c|}{ Hệ số tương quan } \\
\cline { 4 - 7 } & & & DTN & KCN & TTL & CNL \\
\hline DTN & 0.935 & 0.672 & 1.000 & & & \\
\hline KCN & 0.896 & 0.633 & 0.896 & 1.000 & & \\
\hline TTL & 0.927 & 0.717 & 0.924 & 0.923 & 1.000 & \\
\hline CNL & 0.885 & 0.720 & 0.869 & 0.851 & 0.886 & 1.000 \\
\hline
\end{tabular}

Ghi chú: CR (Composite Reliability): Độ tin cậy tổng hợp; AVE (Average Variance Extracted): Phương sai trích trung bình.

Nguồn: Trích xuất từ phân tích dữ liệu thu thập

Bảng 2 thể hiện hệ độ tin cậy tổng hợp CR của DTN, KCN, TTL và CNL được tính toán đều có kết quả lớn hơn 0.70 đảm bảo yêu cầu về độ tin cậy. Hơn nữa hệ số AVE của các nhân tố này cũng được tính toán với kết quả lớn hơn 0.50 , do đó các thang đo của các nhân tố đạt được giá trị hội tụ. Hơn nữa hệ số tương quan cặp giữa các nhân tố khác nhau đều có giá trị nhỏ hơn 1 , trong đó hệ số tương quan lớn nhất là 0.924 đối với cặp nhân tố TTL và DTN, hệ số tương quan nhỏ nhất là 0.851 đối với cặp nhân tố $\mathrm{CNL}$ và $\mathrm{KCN}$. Vậy các nhân tố $\mathrm{DTN}, \mathrm{KCN}$, CNL, và TTL đảm bảo yêu cầu về giá trị phân biệt.

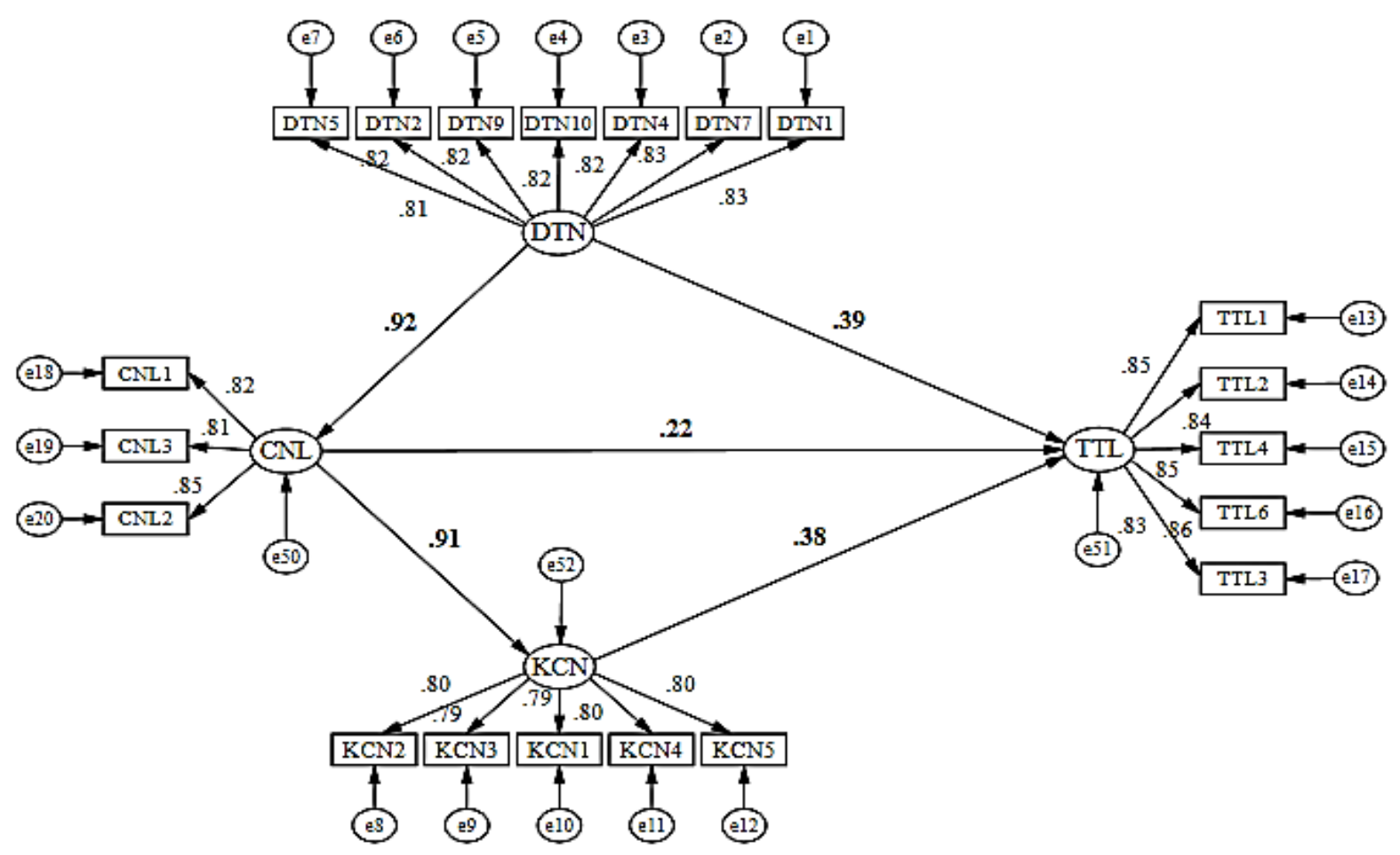

Hình 3. Kết quả SEM (ước lượng chuẩn hóa)

Mô hình nghiên cứu chính thức được ước lượng thể hiện tại Hình 3 với 3 khái niệm phụ thuộc bao gồm TTL, CNL và KCN. Có một khái niệm độc lập là DTN. Kết quả phân tích cho thấy mặc dù Chi-bình phương $\chi 2=253.321$ với $\mathrm{p}=0.000$, tuy nhiên các chỉ tiêu đo lường khác 
đảm bảo yêu cầu: $\mathrm{CMIN} / \mathrm{df}=1.535<3.00, \mathrm{CFI}=0.987>0.90, \mathrm{TLI}=0.985>0.90, \mathrm{RMSEA}$ $=0.037<0.08$. Vậy mô hình là tương thích với dữ liệu thu thập cho nghiên cứu.

\section{Bảng 3}

Ước lượng (chưa chuẩn hóa) và kiểm định các giả thuyết

\begin{tabular}{|c|c|c|c|c|c|c|c|c|}
\hline $\begin{array}{c}\text { Giả } \\
\text { thuyết }\end{array}$ & \multicolumn{3}{|c|}{ Mối quan hệ } & $\begin{array}{l}\text { Hệ số ước } \\
\text { lượng }\end{array}$ & S.E. & C.R. & $\begin{array}{c}\text { Giá trị } \\
\text { p }\end{array}$ & $\begin{array}{c}\text { Kết quả } \\
\text { kiểm định }\end{array}$ \\
\hline $\mathrm{H} 1$ & $\mathrm{KCN}$ & $\rightarrow$ & TTL & 0.432 & 0.099 & 4.349 & $* * *$ & Chấp nhận \\
\hline $\mathrm{H} 2$ & $\mathrm{CNL}$ & $\rightarrow$ & TTL & 0.251 & 0.155 & 1.623 & 0.105 & Tù̀ chối \\
\hline $\mathrm{H} 3$ & $\mathrm{CNL}$ & $\rightarrow$ & $\mathrm{KCN}$ & 0.895 & 0.053 & 16.806 & $* * *$ & Chấp nhận \\
\hline $\mathrm{H} 4$ & DTN & $\rightarrow$ & TTL & 0.414 & 0.095 & 4.367 & $* * *$ & Chấp nhận \\
\hline $\mathrm{H} 5$ & DTN & $\rightarrow$ & CNL & 0.873 & 0.049 & 17.863 & $* * *$ & Chấp nhận \\
\hline
\end{tabular}

(*** tương ứng với $\mathrm{p}$ từ 0.000 đến 0.001 )

Ghi chú: S.E (Standard Error): Sai số chuẩn; C.R. (Critical Ratio): Tỷ số tới hạn.

Nguồn: Kết quả phân tích dữ liệu của nhóm nghiên cứu

Bảng 3 thể hiện kết quả ước lượng chưa chuẩn hóa của các tham số chính của mô hình nghiên cứu chính thức. Với 05 giả thuyết nghiên cứu, chỉ có 01 giả thuyết bị từ chối đó là giả thuyết $\mathrm{H} 2(\mathrm{p}=0.105>0.05)$, điều này có nghĩa là chưa có cơ sở để cho rằng Cam kết nguồn lực có tác động cùng chiều đến Thực thi logistics ngược của Doanh nghiệp bán lẻ hàng điện tử trên địa bàn Thành phố Đà Nẵng, kết quả về mối quan hệ này đã có sự khác biệt so với nghiên cứu của Jack và cộng sự (2010) đã chỉ ra là có sự tác động trực tiếp từ Cam kết nguồn lực đến Thực thi logistics ngược. Tác giả cho rằng sự khác biệt này có thể do thực tiễn trong ngành bán lẻ tại Thành phố Đà Nẵng, Việt Nam với quy mô còn nhỏ lẻ, do đó việc cam kết các nguồn lực tài chính, kỹ thuật và quản lý chưa thực sự đủ mạnh so với các quốc gia phát triển khác trên thế giới. Các giả thuyết nghiên cứu còn lại đều được chấp nhận, bao gồm:

Giả thuyết H1 - Khả năng công nghệ thông tin có tác động tích cực đến Thực thi logistics ngược được chấp nhận. Kết quả này phù hợp với khẳng định trong nghiên cứu của Daugherty và cộng sự (2002) và Closs và cộng sự (1997). Hệ thống công nghệ thông tin sẽ giúp mang lại sự cải tiến nổi trội trong hoạt động logistics ngược và tác động đến kết quả kinh doanh của các doanh nghiệp (Corsi \& Boyson, 2003). Một số tác giả khác cũng đã thừa nhận rằng khả năng công nghệ thông tin sẽ góp phần cải thiện năng lực cạnh tranh trong logistics ngược (Bowersox \& Daugherty, 1995; Patterson et al., 2003). Nghiên cứu này nhận thấy rằng khả năng công nghệ thông tin đã thể hiện được vai trò của biến trung gian giữa Cam kết nguồn lực và Thực thi logistics ngược. Do đó, bên cạnh việc các doanh nghiệp bán lẻ hàng điện tử tập trung vào các mối quan hệ độc lập giữa biến nguyên nhân (Cam kết nguồn lực) và biến kết quả (Thực thi logistics ngược) thì cũng cần chú trọng đến biến trung gian, nghĩa là doanh nghiên cần có sự đầu tư phù hợp nhằm cải thiện khả năng công nghệ thông tin trong quá trình hoạt động cung ứng dịch vụ logistics ngược.

Giả thuyết H3-Cam kết nguồn lực có tác động tích cực đến Khả năng công nghệ thông tin được chấp nhận. Kết quả này cũng phù hợp với nghiên cứu của Daugherty và cộng sự (2002). Khi các nguồn lực được cam kết nhằm mục tiêu xây dựng các khả năng công nghệ thông tin thì hiệu suất của hệ thống công nghệ thông tin sẽ được nâng cao, do đó nhóm tác giả cho rằng doanh nghiệp cần tập trung hơn nữa trong việc đề ra các cam kết cho việc đầu tư các nguồn lực tài chính, kỹ thuật và quản lý, nhằm triển khai các hoạt động logistics ngược hiệu quả hơn. Vai 
trò của việc cam kết nguồn lực càng trở nên quan trọng hơn khi hoạt động liên quan đến việc tiếp nhận, xử lý hàng trả lại càng phức tạp, đặc biệt với lô hàng trả lại có quy mô nhỏ lẻ và thời gian khách hàng trả lại thất thường không tập trung.

Giả thuyết H4 và $\mathrm{H} 5$ cũng được chấp nhận phù hợp với nhận định của các chuyên gia đã đưa ra. Điều này có nghĩa là Danh tiếng doanh nghiệp có tác động trực tiếp đến Cam kết nguồn lực và Thực thi logistics ngược của doanh nghiệp bán lẻ hàng điện tử tại Thành phố Đà Nẵng. Danh tiếng được xem là tài sản vô hình độc đáo, khó có thể bắt chước (Smaiziene \& Jucevicius, 2010). Danh tiếng đại diện cho một tập hợp các ấn tượng của các bên liên quan đối với doanh nghiệp (Guzmán, Abimbola, Shamma, \& Hassan, 2009). Trong lĩnh vực kinh doanh bán lẻ hàng điện tử, việc xây dựng và duy trì danh tiếng trong logistics ngược sẽ góp phần thúc đẩy doanh nghiệp tăng cường hơn nữa trong cam kết nguồn lực cũng như đáp ứng tốt hơn yêu cầu về thực thi logistics ngược cho khách hàng.

\section{Bảng 4}

Tác động trực tiếp, gián tiếp và tổng tác động giữa các khái niệm nghiên cứu (ước lượng chuẩn hóa)

\begin{tabular}{|l|c|c|c|c|}
\hline Biến phụ thuộc & Tác động & $\begin{array}{c}\text { Danh tiếng } \\
\text { doanh nghiệp }\end{array}$ & $\begin{array}{c}\text { Cam kết nguồn } \\
\text { lực }\end{array}$ & $\begin{array}{c}\text { Khả năng công } \\
\text { nghệ thông tin }\end{array}$ \\
\hline \multirow{3}{*}{ Cam kết nguồn lục } & Trực tiếp & 0.920 & & \\
& Gián tiếp & 0.000 & & \\
\hline \multirow{2}{*}{ Khả năng công nghệ } & Trựng tiếp & 0.000 & 0.910 & \\
thông tin & Gián tiếp & 0.837 & 0.000 & \\
\hline \multirow{3}{*}{ Thự thi logistics ngược } & Tổng & $\mathbf{0 . 8 3 7}$ & $\mathbf{0 . 9 1 0}$ & \\
& Trực tiếp & 0.390 & 0.224 & 0.379 \\
& Gián tiếp & 0.523 & 0.345 & 0.000 \\
\hline
\end{tabular}

Nguồn: Xử lý từ dữ liệu khảo sát chính thức

Khác với tác động trực tiếp chỉ xem xét mối quan hệ giữa một biến độc lập vào một biến phụ thuộc thì tác động gián tiếp sẽ xuất hiện trong trường hợp có biến trung gian (Pearl, 2001). Như thể hiện trong mô hình nghiên cứu tại Hình 1 có thể thấy rõ có 03 biến phụ thuộc bao gồm Cam kết nguồn lực, Khả năng công nghệ thông tin và Thực thi logistics ngược, trong đó 02 nhân tố Cam kết nguồn lực và Khả năng công nghệ thông tin đóng vai trò là biến trung gian, điều này dẫn tới ngoài những mối quan hệ tác động trực tiếp tương ứng với các giả thuyết đã đặt ra, còn có những mối quan hệ tác động gián tiếp thông qua các biến trung gian này. Với các hệ số tác động trực tiếp (ước lượng chuẩn hóa) như thể hiện tại Bảng 3 , bằng phương pháp phân tích tương đương trong toán học sẽ tính toán được hệ số tác động gián tiếp. Chẳng hạn như: từ mô hình nghiên cứu cho thấy Danh tiếng doanh nghiệp mặc dù không có quan hệ tác động trực tiếp đến Khả năng công nghệ thông tin nhưng lại có tác động gián tiếp đến Khả năng công nghệ thông tin thông qua nhân tố trung gian là Cam kết nguồn lực. Kết quả ước lượng cho thấy hệ số tác động trực tiếp (chuẩn hóa) từ Danh tiếng doanh nghiệp đến Cam kết nguồn lực là 0.920 , nên có thể viết thành:

$$
\mathrm{CNL}=\beta_{01}+0.920 \times \mathrm{DTN}
$$

Trong khi đó hệ số tác động trực tiếp (chuẩn hóa) từ Cam kết nguồn lực đến Khả năng công nghệ thông tin là 0.910 , nên có thể viết thành: 


$$
\mathrm{KCN}=\beta 02+0.910 \times \mathrm{CNL}
$$

Tiến hành thay (1) vào (2) sẽ có được:

$$
\begin{aligned}
& \mathrm{KCN}=\left(\beta_{02}+0.910 \beta_{01}\right)+(0.910 \times 0.920) \times \mathrm{DTN}, \text { hoặc } \\
& \mathrm{KCN}=\beta_{03}+\mathbf{0 . 8 3 7} \times \mathrm{DTN}
\end{aligned}
$$

( $\beta_{01}, \beta_{02}, \beta_{03}$ : Hệ số chặn tương ứng với (1), (2), (3); $\left.\beta_{03}=\beta_{02}+0.910 \beta_{01}\right)$.

Như vậy, từ (3) cho thấy hệ số tác động gián tiếp từ Danh tiếng doanh nghiệp (DTN) vào Khả năng công nghệ thông tin $(\mathrm{KCN})$ là $\mathbf{0 . 8 3 7}$.

Tính toán tương tự sẽ có kết quả tác động gián tiếp. Kết hợp mức độ tác động gián tiếp với tác động trực tiếp (được trích xuất từ mô hình $\mathrm{SEM}$ ) sẽ có mức độ tổng tác động (lấy hệ số tác động trực tiếp cộng với hệ số tác động gián tiếp) được thể hiện tại Bảng 4. Kết quả cho thấy rằng: Danh tiếng doanh nghiệp có tổng tác động mạnh nhất đến Thực thi logistics ngược với mức độ tổng tác động là 0.913 , các nhân tố Cam kết nguồn lực và Khả năng công nghệ thông tin có tác động đến Thực thi logistics ngược ở mức độ lần lượt là $0.569,0.379$. Nhìn chung mức độ tác động trong các mối quan hệ là đáng kể và phần lớn có ý nghĩa thống kê. Mặc dù tác động trực tiếp của Cam kết nguồn lực đến Thực thi logistics ngược là 0.224 nhưng mối quan hệ này không có ý nghĩa thống kê, điều này có thể do việc cam kết về nguồn lực tài chính, nguồn lực kỹ thuật và nguồn lực quản lý chưa thực sự đủ mạnh trong những thời gian qua, do đó các cam kết này chưa thực sự đóng vai trò nòng cốt trong việc thúc đẩy hoạt động thực thi logistics ngược của doanh nghiệp bán lẻ kinh doanh hàng điện tử trên địa bàn Thành phố Đà Nẵng.

\begin{tabular}{|c|c|c|c|c|c|c|c|c|c|}
\hline \multirow{2}{*}{\multicolumn{3}{|c|}{ Mối quan hệ }} & \multicolumn{2}{|c|}{ Ước lượng ML } & \multicolumn{5}{|c|}{ Ước lượng Bootstrap } \\
\hline & & & M & SE & SE & SE(SE) & M & Bias & SE(Bias) \\
\hline $\mathrm{KCN}$ & $\rightarrow$ & TTL & 0.560 & 0.067 & 0.085 & 0.002 & 0.560 & 0.000 & 0.003 \\
\hline $\mathrm{CNL}$ & $\rightarrow$ & $\mathrm{KCN}$ & 0.895 & 0.053 & 0.059 & 0.001 & 0.897 & 0.002 & 0.002 \\
\hline DTN & $\rightarrow$ & TTL & 0.534 & 0.061 & 0.074 & 0.002 & 0.533 & -0.001 & 0.002 \\
\hline DTN & $\rightarrow$ & CNL & 0.876 & 0.049 & 0.048 & 0.001 & 0.879 & 0.003 & 0.002 \\
\hline
\end{tabular}

\section{Bảng 5}

Kết quả ước lượng (chưa chuẩn hóa) bằng bootstrap với $\mathrm{N}=1000$

Ghi chú: ML: ước lượng theo phương pháp Maximum Likelihood; M: hệ số ước lượng theo phương pháp ML; SE: sai chuẩn; Bias: độ chệch

Nguồn: Kết quả xử lý dữ liệu điều tra

Mô hình nghiên cứu trong phân tích bootstrap không xem xét mối quan hệ giữa Cam kết nguồn lực và Thực thi logistics ngược vì không có ý nghĩa thống kê với kết quả như trình bày tại Bảng 5 . Việc sử dụng phân tích bootstrap sẽ cho phép lấy mẫu lại dựa trên mẫu nghiên cứu ban đầu, điều này sẽ giúp tránh việc phải khảo sát lại để đánh giá vì tốn kém nhiều thời gian và chi phí (Anderson \& Gerbing, 1988; Nguyen \& Nguyen, 2011). Nghiên cứu này sử dụng phương pháp Bootstrap với số mẫu lặp lại $\mathrm{N}=1000$, kết quả phân tích cho thấy độ chệch giữa ước lượng bằng Bootstrap và $\mathrm{ML}$ không đáng kể, độ chệch ước lượng lớn nhất chỉ bằng 0.003 trong mổi quan hệ giữa $\mathrm{DTN}$ và $\mathrm{CNL}$, độ chệch ước lượng thấp nhất là 0.001 trong mối 
quan hệ giữa DTN và TTL. Vậy các ước lượng trong mô hình nghiên cứu điều chỉnh đảm bảo được về tính tin cậy.

\section{Hàm ý nghiên cứu và kết luận}

\subsection{Hàm ý nghiên cúu}

Bên cạnh những ý nghĩa có được từ mô hình đo lường và mô hình lý thuyết nghiên cứu, một số hàm ý liên quan trong lĩnh vực kinh doanh bán lẻ hàng điện tử cụ thể như sau:

Thứ nhất, các nhà hoạch định chính sách, cơ quan quản lý nhà nước cần tiếp tục rà soát và đẩy mạnh hơn nữa việc ban hành những quy định liên quan đến phạm vi quản lý hoạt động logistics ngược. Yêu cầu các doanh nghiệp thực hiện nghiêm túc hoạt động kinh doanh các sản phẩm đảm bảo không gây tác hại đến môi trường. Có biện pháp giúp doanh nghiệp và khách hàng nâng cao nhận thức cũng như trách nhiệm xã hội về vấn đề môi trường. Với các quy định ban hành kịp thời sẽ giúp các doanh nghiệp bán lẻ và người tiêu dùng các sản phẩm điện tử có cơ sở để tuân thủ tốt hơn các quy định. Bên cạnh đó, cần vận dụng các chỉ số môi trường vào việc đánh giá doanh nghiệp bán lẻ hàng điện tử tại Đà Nẵng trong quá trình triển khai logistics ngược hướng đến mục tiêu thành phố môi trường.

Thứ hai, các kết quả của nghiên cứu cung cấp ý nghĩa thực tiễn cho lĩnh vực bán lẻ hàng điện tử. Việc xử lý nhanh chóng nhằm phục hồi giá trị của các sản phẩm trả lại sẽ góp phần mang lại lợi ích cho khách hàng tốt hơn, từ đó làm hài lòng khách hàng và tăng cơ hội bán hàng trong tương lai. Ngoài ra, các doanh nghiệp bán lẻ là đơn vị gần gũi nhất với người tiêu dùng trong chuỗi phân phối và do đó có thể đạt được tỷ lệ thu hồi sản phẩm cao hơn so với các nhà bán buôn, nhà phân phối hoặc nhà sản xuất. Bằng cách thực thi logistics ngược, các công ty có thể tăng lợi nhuận và năng suất của họ vì điều này góp phần giảm chi phí.

Thứ ba, kết quả nghiên cứu cũng cho thấy sản phẩm trả lại là một phần quan trọng của logistics ngược, đi kèm với đó là việc đưa ra biện pháp để xử lý các mặt hàng trả lại và điều này sẽ mang lại cho doanh nghiệp bán lẻ những kết quả về khía cạnh kinh tế và môi trường. Trong phạm vi của doanh nghiệp bán lẻ, các lựa chọn giải quyết các sản phẩm trả lại có thể bao gồm những hoạt động như tân trang, sửa chữa, cũng như xử lý phế thải. Do đó, để làm tốt hoạt động này đòi hỏi các nhà quản lý cần thiết phải đánh giá chính xác từng sản phẩm được trả lại để xác định tùy chọn xử lý một cách tối ưu nhất, vì nếu được quản lý đúng cách, doanh nghiệp sẽ có cơ hội để khai thác lợi ích trong quá trình thực thi logistics ngược.

Thứ tư, kết quả nghiên cứu cho thấy Thực thi logistics ngược của Doanh nghiệp bán lẻ hàng điện tử trên địa bàn Thành phố Đà Nẵng chịu sự tác động trực tiếp lớn nhất từ Khả năng công nghệ thông tin, tiếp đến là Danh tiếng doanh nghiệp, và Cam kết nguồn lực. Mặc dù không có cơ sở để kết luận Cam kết nguồn lực có tác động trực tiếp đến Thực thi logistics ngược nhưng Cam kết nguồn lực có tác động gián tiếp đến Thực thi logistics ngược thông qua Khả năng công nghệ thông tin. Thông qua kết quả có được, kỳ vọng doanh nghiệp bán lẻ hàng điện tử sẽ nắm bắt rõ hơn và có thể vận dụng tốt vào công tác thực thi logistics ngược bằng cách đề ra biện pháp hữu hiệu nhằm mang lại hiệu quả trong quá trình hoạt động, chẳng hạn:

(i) Về Thưc thi logistics ngượ: Mặc dù thực thi logistics ngược có phạm vi khá rộng rãi bao gồm thực hiện các hoạt động thu gom, vận chuyển, sửa chữa, tân trang, tái chế các sản phẩm và bao bì đóng gói trả lại từ khách hàng, tháo gỡ các sản phẩm trả lại để sử dụng lại các nguyên vật liệu, tiêu hủy, xử lý chôn lấp các phế thải, tiếp nhận dòng thông tin phản hồi. Tuy nhiên trong phạm vi của ngành bán lẻ hàng điện tử tại Thành phố Đà Nẵng, các hoạt động thuộc 
nội dung thực thi logistics ngược thì chưa được doanh nghiệp bán lẻ thực hiện một cách đầy đủ, chẳng hạn như chưa thực hiện hoạt động tái chế sản phẩm trả lại, chưa thực hiện việc tháo gỡ các sản phẩm nhằm mục đích sử dụng lại các nguyên vật liệu, cũng như chưa thể thực hiện việc xử lý tiêu hủy và chôn lấp phế thải. Nghiên cứu này cho rằng những hoạt động này khó để thực hiện tại tại cấp bán lẻ vì khá phức tạp đòi hỏi yếu tố về mặt công nghệ mà chỉ có các hãng sản xuất mới có khả năng thực hiện được.

Thực tiễn về thực thi logistics ngược tại doanh nghiệp bán lẻ hàng điện tử tại Đà Nẵng mới chỉ dừng lại ở một số hoạt động như thu gom, vận chuyển hàng trả lại nhằm mục đích sửa chữa, tân trang ở mức độ đơn giản mà dễ dàng nhìn thấy ở các mặt hàng điện thoại di động, máy giặt, tủ lạnh, điều hòa nhiệt độ, nhận đổi trả hàng trong thời gian bảo hành cho khách hàng, thu mua các sản phẩm cũ nhưng còn sử dụng được để tân trang để bán lại (xuất hiện ở một số nhà bán lẻ thu mua và bán sản phẩm đã qua sử dụng như điện thoại di động cũ, quạt điện, điều hòa cũ, bình điện cũ). Bên cạnh đó doanh nghiệp bán lẻ hàng điện tử tại Thành phố Đà Nẵng cũng thực hiện các hoạt động trả lại sản phẩm, bao bì đóng gói theo chính sách mà nhà cung cấp đưa ra. Tuy nhiên có thể nói mức độ thực hiện các hoạt động liên quan đến thực thi logistics ngược mới chỉ tập trung cao đối với các sản phẩm điện tử trả lại trong thời gian bảo hành và các hoạt động cung ứng dịch vụ sửa chữa, tân trang ở mức độ vừa phải.

Do đó, nghiên cứu này cho rằng các doanh nghiệp cần tích cực quan tâm thực hiện tốt hơn nữa công tác lập kế hoạch thu gom, vận chuyển các sản phẩm điện tử hết hạn sử dụng, bị lỗi, kém chất lượng và bao bì đóng gói mà trước đây đã bán cho khách hàng. Sẵn sàng ứng phó và tiếp nhận, thu hồi các sản phẩm gặp vấn đề về chất lượng, đáp ứng kịp thời chính sách thu hồi từ phía nhà cung cấp. Trong phạm vi khả năng của doanh nghiệp bán lẻ hàng điện tử, có thể cung ứng một số dịch vụ sửa chữa các hư hỏng mà khách hàng thường gặp phải, cung cấp các dịch vụ tân trang, thay thế linh kiện, phụ kiện sản phẩm khi khách hàng có nhu cầu. Từ đó góp phần tiết kiệm thời gian và giúp khách hàng hài lòng hơn về sản phẩm và dịch vụ mà doanh nghiệp cung cấp. Khi gặp tình huống khách hàng trả lại sản phẩm nhưng nằm ngoài phạm vi xử lý ở cấp độ bán lẻ hàng điện tử, doanh nghiệp bán lẻ có thể thông báo kịp thời đến các đơn vị liên quan trong chuỗi cung ứng để có biện pháp xử lý thích hợp. Thực hiện đầy đủ các chế độ bảo hành sản phẩm cũng như tuân thủ các nguyên tắc hoàn trả mà doanh nghiệp đã cam kết với khách hàng.

(ii) Về Cam kết nguồn lưc: Như thể hiện trong mô hình đề xuất nghiên cứu, Cam kết nguồn lực là biến trung gian giữa Danh tiếng doanh nghiệp và Khả năng công nghệ thông tin, giữa Danh tiếng doanh nghiệp và Thực thi logistics ngược. Mặc dù chưa thể kết luận được Cam kết nguồn lực tác động trực tiếp đến Thực thi logistics ngược trong bối cảnh ngành điện tử tại Thành phố Đà Nẵng, nhưng sự tác động gián tiếp đến Thực thi logistics ngược của Cam kết nguồn lực thông qua Khả năng công nghệ thông tin đã thể hiện. Điều này cho thấy Cam kết nguồn lực đến Thực thi logistics ngược có vai trò không kém phần quan trọng đối với doanh nghiệp bán lẻ mặt hàng điện tử. Do đó doanh nghiệp nên chú ý tăng cường thể hiện các thông điệp mạnh mẽ mang tính cam kết trong đầu tư các nguồn lực một cách phù hợp nhằm thúc đẩy sự phát triển khả năng công nghệ thông tin và từ đó đẩy mạnh hoạt động thực thi logistics ngược;

(iii) Về Danh tiếng doanh nghiệp: Tiếp tục duy trì và nâng cao hơn nữa danh tiếng doanh nghiệp trong logistics ngược. Để thực hiện được điều này, đòi hỏi doanh nghiệp cần thường xuyên bày tỏ sự quan tâm sâu sát đối với nhu cầu trả lại sản phẩm của khách hàng, chủ động trong công tác chăm sóc khách hàng và qua đó tìm hiểu khách hàng về khả năng trả lại các sản 
phẩm điện tử mà họ đã mua trước đây. Bên cạnh đó doanh nghiệp bán lẻ cần quán triệt đến toàn thể cán bộ nhân viên của mình luôn đảm bảo giữ vững thái độ nhã nhặn lịch sự một khi nhận được sự trả lại sản phẩm từ khách hàng, đảm bảo quyền lợi của khách hàng trả lại hàng một cách nghiêm túc, quan tâm đến tất cả các khách hàng với bất kể giá trị nào của sản phẩm trả lại, đảm bảo uy tín với khách hàng làm cho khách hàng cảm thấy hài lòng. Hơn nữa trong quá trình xử lý các sản phẩm trả lại, doanh nghiệp bán lẻ hàng điện tử cần nâng cao hơn nữa tinh thần trách nhiệm xã hội và trách nghiệm môi trường; và

(iv) Về Khả năng công nghệ thông tin: Được xem là nhân tố không thể thiếu được trong quá trình phát triển của xã hội nói chung trong đó có các doanh nghiệp. Như thể hiện tại các kết quả nghiên cứu, Khả năng công nghệ thông tin tác động trực tiếp đáng kể đến Thực thi logistics ngược. Vì thế doanh nghiệp cần tiếp tục nghiên cứu, tiếp cận sự thay đổi của các hệ thống công nghệ thông tin, để từ đó đưa ra quyết định đầu tư một cách thích đáng, phù hợp với nguồn lực tài chính, góp phần thúc đẩy thực thi logistics ngược thuận lợi hơn. Một khi doanh nghiệp đạt được sự lớn mạnh về khả năng công nghệ thông tin, doanh nghiệp bán lẻ hàng điện tử sẽ trở nên thuận lợi trong việc kết nối với khách hàng, nhà cung cấp và các cơ quan quản lý nhà nước. Dễ dàng trong việc thiết lập hệ thống cơ sở dữ liệu tốt hơn, tăng khả năng truyền thông các hoạt động nổi trội của logistics ngược đến với khách hàng và nhà cung cấp, tạo sự thuận tiện cho doanh nghiệp bán lẻ thực hiện các nội dung thông báo liên quan đến tiến độ xử lý một cách linh hoạt sản phẩm, bao bì đóng gói trả lại để mang đến hiệu quả, sự tiện lợi cũng như đáp ứng mong đợi cho khách hàng.

\subsection{Kết luận}

Thực thi logistics ngược chịu sự tác động của 03 nhân tố chính bao gồm Khả năng công nghệ thông tin, Danh tiếng doanh nghiệp (được khám phá thông qua phương pháp nghiên cứu định tính) và Cam kết nguồn lực (đóng vai trò trung gian, tác động gián tiếp đến Thực thi logistics ngược thông qua Khả năng công nghệ thông tin). Kết quả của nghiên cứu này cho phép doanh nghiệp nâng cao hơn nữa về mặt nhận thức vai trò của Thực thi logistics ngược, doanh nghiệp có thể xem xét thực hiện một số biện pháp nhằm cải thiện hiệu quả hoạt động logistics ngược bằng cách tiếp tục nâng cao danh tiếng doanh nghiệp, tăng cường trong công tác cam kết nguồn lực, thúc đẩy đầu tư vào hệ thống công nghệ thông tin cũng như chú trọng trong công tác lập kế hoạch cho hoạt động logistics ngược trong lĩnh vực bán lẻ hàng điện tử. Trong quá trình nghiên cứu, bên cạnh những kết quả đạt được có ý nghĩa, nghiên cứu cũng bộc lộ những hạn chế khó có thể tránh khỏi chẳng hạn như hạn chế về phạm vi nghiên cứu, đề tài chỉ nghiên cứu tập trung đối với hoạt động logistics ngược của doanh nghiệp bán lẻ và chỉ cụ thể hóa đối với bán lẻ hàng điện tử tại địa bàn Thành phố Đà Nẵng. Có thể kết quả sẽ có sự khác biệt đối với những phạm vi nghiên cứu khác chẳng hạn như hoạt động logistics ngược của doanh nghiệp sản xuất hoặc của các trung gian phân phối khác. Nghiên cứu mới dừng lại ở một số tác nhân nhất định trong logistics ngược, có thể còn nhiều nhân tố khác cũng được xem là tác nhân của Thực thi logistics ngược như Áp lực từ thể chế, Chủ nghĩa cơ hội, Khả năng liên kết ngược và Nhận thức nhà quản lý về logistics ngược. Nhóm nghiên cứu kỳ vọng những hạn chế này sẽ được tiếp tục giải quyết trong những giai đoạn tiếp theo. 


\section{Tài liệu tham khảo}

Agle, B. R., Mitchell, R. K., \& Sonnenfeld, J. A. (1999). Who matters to CEOS? An investigation of stakeholder attributes and salience, corpate performance, and ceo values. Academy of Management Journal, 42(5), 507-525. doi:10.5465/256973

Anderson, J. C., \& Gerbing, D. W. (1988). Structural equation modeling in practice: A review and recommended two-step approach. Psychological Bulletin, 103(3), 411-423. doi:10.1037/0033-2909.103.3.411

Autry, C. W., Daugherty, P. J., \& Richey, R. G. (2001). The challenge of reverse logistics in catalog retailing. International Journal of Physical Distribution \& Logistics Management, 31(1), 26-37. doi:10.1108/09600030110366384

Barney, J. B. (1986). The resource based theory of the firm. Organizational Science, 26(1), 4156.

Barney, J. B. (1991). Firm resources and sustained competitive advantage. Journal of Management, 17(1), 99-120. doi:10.1177/014920639101700108

Barney, J. B. (2014). Gaining and sustaining competitive advantage. Harlow, UK: Pearson Education Limited.

Bernon, M., Rossi, S., \& Cullen, J. (2011). Retail reverse logistics: A call and grounding framework for research. International Journal of Physical Distribution \& Logistics Management, 41(5), 484-510. doi:10.1108/09600031111138835

Blumberg, D. (1999). Strategic examination of reverse logistics \& repair service requirements, needs, market size, and opportunities. Journal of Business Logistics, 22(2), 141-159.

Bollen, K. A. (1989). A new incremental fit index for general structural equation models. Research Article, 17(3), 303-316. doi:10.1177/0049124189017003004

Bowersox, D. J., \& Daugherty, P. J. (1995). Logistics paradigms: The impact of information technology. Journal of Business Logistics, 16(1), 65-80.

Carter, C. R., \& Ellram, L. M. (1998). Reverse logistics: A review of the literature and framework for future investigation. International Journal of Business Logistics, 19(1), 85-122.

Cleveland, H., \& Jacobs, G. (1999). Human choice: The genetic code for social development. Futures, 31(9-10), 959-970. doi:10.1016/S0016-3287(99)00055-5

Closs, D. J., Goldsby, T. J., \& Clinton, S. R. (1997). Information technology influences on world class logistics capability. International Journal of Physical Distribution \& Logistics Management, 27(1), 4-17.

Closs, D. J., \& Savitskie, K. (2003). Internal and external logistics information technology integration. The International Journal of Logistics Management, 14(1), 63-76.

Closs, D. J., \& Xu, K. (2000). Logistics information technology practice in manufacturing and merchandising firms - An international benchmarking study versus world class logistics firms. International Journal of Physical Distribution \& Logistics Management, 30(10), 869-886. 
Công ty CP Gemadept. (2018). Bản tin Logistics [Logistics news]. Retrieved September 11, 2019 , from http://www.gemadept.com.vn/assets/uploads/myfiles/files/BanTin/Logistics/BAN\%20T IN \%20LOGISTICS_THANG\%2006-2015.pdf

Corsi, T. M., \& Boyson, S. (2003). Real-time e-supply chain management: Diffusion of new technologies and business practices. Transportation research part E: Logistics and Transportation Review, 39(2), 79-82.

Daugherty, P. J., Myers, M. B., \& Richey, G. R. (2002). Information support for reverse logistics: The influence of relationship commitment. Journal of Business Logistics, 23(1), 85-106. doi:10.1002/j.2158-1592.2002.tb00017.x

Dawe, R. L. (1994). An investigation of the pace and determination of information technology use in the manufacturing materials logistics system. Journal of Business Logistics, 15(1), 229-260.

Day, G. S. (1994). The capabilities of market-driven organizations. Journal of Marketing, 58(4), 37-52.

Dias, K. T., \& Braga, S. S., Jr. (2016). The use of reverse logistics for waste management in a Brazilian grocery retailer. Waste Management \& Research, 34(1), 22-29.

Doney, P. M., \& Cannon, J. P. (1997). An examination of the nature of trust in buyer-seller relationships. Journal of Marketing, 61(2), 35-51. doi:10.1177/002224299706100203

Dowling, G. (1994). Corporate reputations: Strategies for developing the corporate brand. England: Longman Cheshire.

Dowling, G. (2000). Creating corporate reputations: Identity, image and performance: Identity, image and performance. Oxford, UK: Oxford University Press.

Ellram, L. M., La Londe, B. J., \& Weber, M. M. (1989). Retail logistics. International Journal of Physical Distribution \& Materials Management, 19(12), 29-39. doi:10.1108/EUM0000000000348

Fombrun, C. J. (1996). Realizing value from the corporate image. Boston, MA: Harvard Business School Press.

Fombrun, C. J., \& Rindova, V. P. (2000). The road to transparency: Reputation management at Royal Dutch/Shell. The Expressive Organization, 7, 7-96.

Fombrun, C., \& Shanley, M.(1990). What's in a name? Reputation building and corporate strategy. Academy of Management Journal, 33(2), 233-258.

Georgiadis, P., \& Besiou, M. (2010). Environmental and economical sustainability of WEEE closed-loop supply chains with recycling: A system dynamics analysis. The International Journal of Advanced Manufacturing Technology, 47(5/8), 475-493.

Govindan, K., Soleimani, H., \& Kannan, D. (2015). Reverse logistics and closed-loop supply chain: A comprehensive review to explore the future. European Journal of Operational Research, 240(3), 603-626. 
Guiltinan, J. P., \& Nwokoye, N. G. (1975). Developing distribution channels and systems in the emerging recycling industries. International Journal of Physical Distribution, 6(1), 2838. doi:10.1108/eb014359

Guzmán, F., Abimbola, T., Shamma, H. M., \& Hassan, S. S. (2009). Customer and noncustomer perspectives for examining corporate reputation. Journal of Product \& Brand Management, 5(18), 326-337. doi:10.1108/10610420910981800

Hair, J. F., Black, W. C., Babin, B. J., \& Anderson, R. E. (1998). Multivariate data analysis. Upper Saddle River, NJ: Prentice Hall.

Hair, J. F., Black, W. C., Babin, B. J., \& Anderson, R. E. (2010). Multivariate data analysis: Global edition. Upper Saddle River, NJ: Pearson Higher Education.

Herbig, P., \& Milewicz, J. (1993). The relationship of reputation and credibility to brand success. Journal of Consumer Marketing, 10(3), 18-24. doi:10.1108/EUM0000000002601

Hoelter, K. A. (1990). Overall fit in covariance structure models: Two types of sample size effects. Psychological Bulletin, 107(2), 256-259.

Jack, E. P., Powers, T. L., \& Skinner, L. (2010). Reverse logistics capabilities: Antecedents and cost savings. International Journal of Physical Distribution \& Logistics Management, 40(3), 228-246. doi:10.1108/09600031011035100

Jacobs, G., Macfarlane, R., \& Asokan, N. (1997). Comprehensive theory of social development. International Center for Peace and Development Napa. Retrieved September 15, 2019, from https://www.icpd.org/development_theory/comprehensive_theory_of_ social_development.htm

Lambert, D. M., \& Stock, J. R. (1981). Strategic physical distribution management. Homewood, IL: Irwin.

Lewis, I., \& Talalayevsky, A. (2000). Third-party logistics: Leveraging information technology. Journal of Business Logistics, 21(2), 173-186.

Marchesini, M. M. P., \& Alcântara, R. L. C. (2016). Logistics activities in supply chain business process: A conceptual framework to guide their implementation. The International Journal of Logistics Management, 27(1), 6-30.

Nguyen, D. T., \& Nguyen, T. M. T. (2011). Nghiên cứu khoa học marketing úng dụng mô hình cấu trúc tuyến tính SEM [Research on marketing science using SEM linear structure model]. Hanoi, Vietnam: NXB Lao động.

Parente, J. G., \& Terepins, F. M. (2009). Responsabilidade social empresarial do varejo no Brasil. Ensino e Pesquisa, 10(4), 109-132.

Patterson, K. A., Grimm, C. M., \& Corsi, T. M. (2003). Adopting new technologies for supply chain management. Transportation Research Part E: Logistics and Transportation Review, 39(2), 95-121.

Pearl, J. (2001). Direct and indirect efects. Proceedings of the Seventeenth Conference on Uncertainy in Arti cial Intel ligence, 4(1), 11-21.

Penrose, E. T. (1959). The theory of the growth of the firm. New York, NY: Wiley. 
RevLog. (1998). The European Working group on Reverse Logistics (1998-). Retrieved September 11, 2019, from http://www.fbk.eur.nl/OZ/REVLOG/

Richey, G. R., \& Wheeler, A. R. (2004). A new framework for supply chain manager selection: Three hurdles to competitive advantage. Journal of Marketing Channels, 11(4), 89-103.

Rogers, D. S., \& Tibben-Lembke, R. S. (1999). Going backwards: Reverse logistics trends and practices. Pittsburgh, PA: RLEC Press.

Siltaoja, M. E. (2006). Value priorities as combining core factors between CSR and reputation - A qualitative study. Journal of Business Ethics, 68(1), 91-111.

Smaiziene, I., \& Jucevicius, R. (2010). Organizations and competitiveness. Facing multidimensional nature of corporate reputation: Challenges for managing reputation. Social Sciences/Socialiniai Mokslai, 3(69), 48-56.

Srinivasan, R., Lilien, G. L., \& Rangaswamy, A. (2002). Technological opportunism and radical technology adoption: An application to e-business. Journal of Marketing, 66(3), 47-60.

Steenkamp, J.-B. E. M., \& van Trijp, H. C. M. (1991). The use of lisrel in validating marketing constructs. International Journal of Research in Marketing, 8(4), 283-299. doi:10.1016/0167-8116(91)90027-5

Stock, J. R. (1992). Reverse logistics. Oak Brook, IL: Council of Logistics Management.

Sundarraj, R. P., \& Talluri, S. (2003). A multi-period optimization model for the procurement of component-based enterprise information technologies. European Journal of Operational Research, 146(2), 339-351.

Walsh, G., \& Beatty, S. E. (2007). Customer-based corporate reputation of a service firm: Scale development and validation. Journal of the Academy of Marketing Science, 35(1), 127143. doi:10.1007/s11747-007-0015-7

Wernerfelt, B. (1995). The resource-based view of the firm: Ten years after. Strategic Management Journal, 16(3), 171-174.

Ye, F., Zhao, X., Prahinski, C., \& Li, Y. (2013). The impact of institutional pressures, top managers' posture and reverse logistics on performance - Evidence from China. International Journal of Production Economics, 143(1), 132-143.

Zacharia, Z. G., Sanders, N. R., \& Nix, N. W. (2011). The emerging role of the Third-Party Logistics Provider (3PL) as an orchestrator. Journal of Business Logistics, 32(1), 40-54. doi:10.1111/j.2158-1592.2011.01004

Zhou, K. Z., Yim, C. K., \& Tse, D. K. (2005). The effects of strategic orientations on technology - and market-based breakthrough innovations. Journal of Marketing, 69(2), 42-60. doi:10.1509/jmkg.69.2.42.60756 